University of Louisville

ThinkIR: The University of Louisville's Institutional Repository

Electronic Theses and Dissertations

$12-2013$

\title{
The dimerization of parotid secretory protein.
}

Diana M. Blau

University of Louisville

Follow this and additional works at: https://ir.library.louisville.edu/etd

\section{Recommended Citation}

Blau, Diana M., "The dimerization of parotid secretory protein." (2013). Electronic Theses and Dissertations. Paper 116.

https://doi.org/10.18297/etd/116

This Master's Thesis is brought to you for free and open access by ThinkIR: The University of Louisville's Institutional Repository. It has been accepted for inclusion in Electronic Theses and Dissertations by an authorized administrator of ThinkIR: The University of Louisville's Institutional Repository. This title appears here courtesy of the author, who has retained all other copyrights. For more information, please contact thinkir@louisville.edu. 
THE DIMERIZATION OF PAROTID SECRETORY PROTEIN

By

Diana M. Blau

M.S., 2013

\begin{abstract}
A Thesis
Submitted to the Faculty of the

University of Louisville School of Dentistry

In Partial Fulfillment of the Requirements

For the Degree of
\end{abstract}

Masters of Science

School of Dentistry - Department of Oral Health and Rehabilitation

University of Louisville

Louisville, KY

December, 2013 



\title{
THE DIMERIZATION OF PAROTID SECRETORY PROTEIN
}

\author{
by \\ Diana M. Blau \\ A Thesis Approved on
}

August 14, 2013

By the following Thesis Committee:

Dr. Douglas Darling

Dr. Brian Shumway

Dr. Jan Potempa 


\section{ACKNOWLEDGEMENTS}

I would like to take this opportunity to thank the many people that have helped me in the completion of this document. I feel very privileged to have had the opportunity to work in the Douglas Darling lab at the University of Louisville School of Dentistry. In this lab, I spent many hours designing experiments and many days seeing them through. The collaborative effort of each member of the lab made everything in this paper possible and I am forever grateful for the amount of knowledge and skill my lab mates shared with me throughout the years. Thank you to: Anne Carenbauer, Srirangapatnam G. Venkatesh, Dipti Goyal, and Melissa A. Metzler, for all the support and teamwork you displayed. I am also thankful for the members of my thesis committee: Dr. Jan Potempa and Dr. Brian Shumway. Your efforts in expanding my understanding and depth of this project have truly helped my research in a positive way.

I would especially like to thank Dr. Douglas Darling for believing in me and giving me endless encouragement and wisdom. I truly enjoyed my time in your lab and working under your guidance. You have shown me the value and importance of research and have opened my eyes to the possibilities in making this a career. I can't thank you enough. 


\section{ABSTRACT \\ THE DIMERIZATION OF PAROTID SECRETORY PROTEIN \\ Diana Blau}

August 14, 2013

BACKGROUND: The parotid gland plays an integral part in digestion, immunity, and oral health. Parotid Secretory Protein (PSP, BPIFA2E) is an abundant protein that is secreted into the oral cavity. To understand the unique molecular mechanisms of sorting secretory proteins, structure must be studied. Protein structure is essential in understanding the basis of function.

HYPOTHESIS: We hypothesize that PSP in solution forms a dimer . METHODS: Initially, parotid secretory granules were purified from rat parotid glands by using differential centrifugation and crosslinked with formaldehyde. The products were analyzed by SDS-PAGE and Western blot for PSP. Using PCR technology our gene of interest (PSP) was fused with an epitope tag (V5 or HA). The PSP cDNA was also cloned in-frame with Gluthathione S-transferase (GST) in the pGEX 4T-3 vector. The GST-PSP fusion protein was expressed in BL21DE3 (p-LysE) bacteria. GST-PSP, or GST (control), was immobilized on glutathione sepharose resin. TNT reticulocyte lysates synthesized the PSP-V5 protein, and it was incubated with the immobilized GST-PSP. Analysis of bound PSP-V5 was done by Western blots probed with anti-V5 and anti-PSP antibodies.

RESULTS: Formaldehyde crosslinking of parotid secretory granules created a new antiPSP immunoreactive species with twice the apparent size of PSP, suggesting 
dimerization of PSP. An alternative approach used affinity binding of in vitro synthesized PSP. Anti-V5 western blot analysis shows repeatable binding of PSP-V5 to the GST-PSP resin, but little or no binding to the GST resin as a negative control. This indicates multimerization of PSP on the affinity column. Computational prediction of quaternary structure suggests two separate classes of PSP dimer models, either stacked or head-tohead. PSP mutants were created by deleting possible dimer formation areas, and affinity binding experiments supported the head-to-head dimer model. PSP mutants which cannot form dimers also cannot bind lipids.

CONCLUSION: These experiments show PSP binding to itself as a dimer. This quarternary structure may be important for the function of PSP, such as binding to lipids. This groundwork will lay the foundation for the crystallization of PSP for future exploration. Supported by NIH DE019243. 


\section{TABLE OF CONTENTS}

PAGE

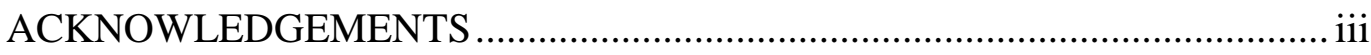

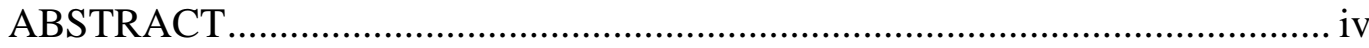

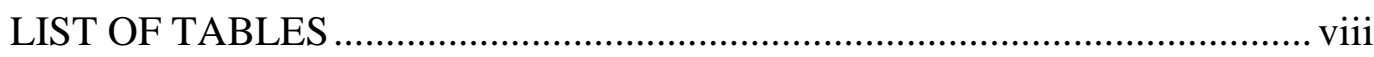

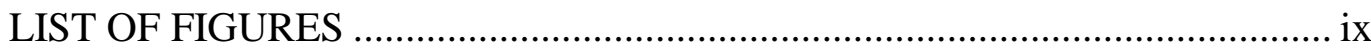

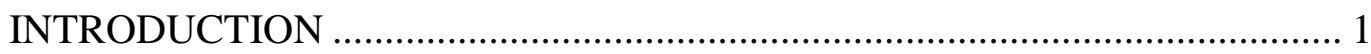

MATERIALS AND METHODS ................................................................

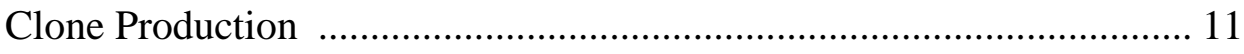

Purification of Fusion Protein ............................................................. 17

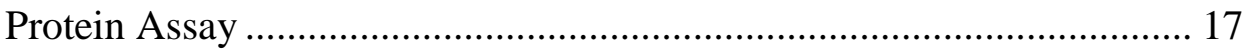

Isolation of Parotid Secretory Granules ................................................. 18

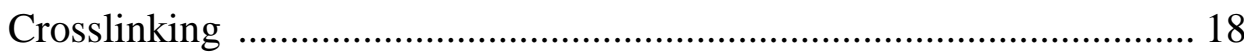

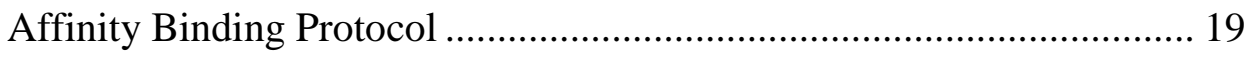

Computer Modeling of Quaternary Structure ………............................... 20

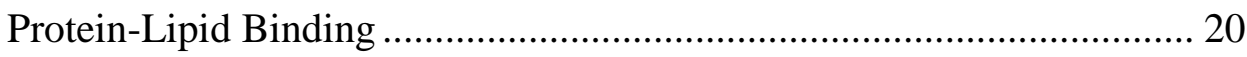

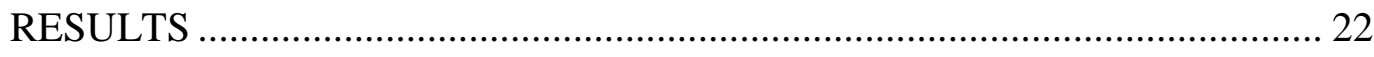

Crosslinking with Formaldehyde/ $\mathrm{Bst}^{3}$............................................... 22

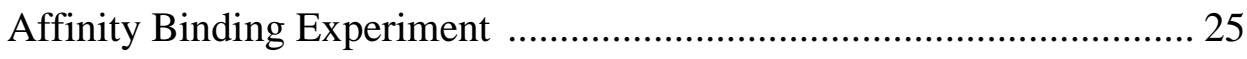

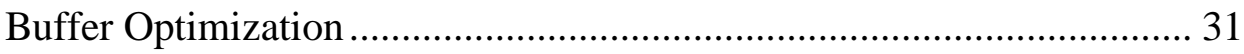


Chlorampenicol Acetlytransferase (CAT) Control Experiment ............ 34

Human PSP Experiments .......................................................... 35

Titration of reticulocyte lysate to resin ............................................ 37

I-Tasser Computer modeling ........................................................ 42

Symmdock Dimerization Modeling …............................................ 46

Rosetta Software 3-D Modeling ..................................................... 51

Testing Stacked Dimer Model with Mutants ....................................... 55

Testing Dimer Model \#2 (End-to-End model) ..................................... 59

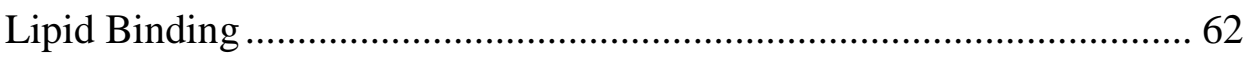

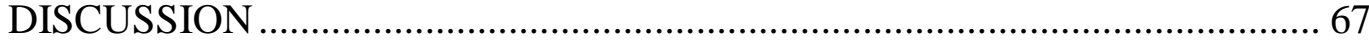

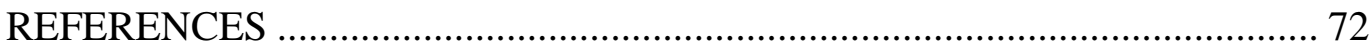

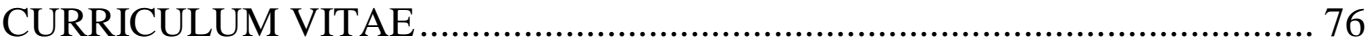




\section{LIST OF TABLES}

\section{TABLE}

1. List of Expression Vector pGEX4T-3 Clones for studying the expression and dimerization of Parotid Secretory Protein ................................................................................. 12

2. List of Expression Vector pcDNA 6.2 clones for studying the expression and dimerization of Parotid Secretory Protein ............................................................................. 14

3. TOPO Vector PCR Conditions ……………………...................................... 15

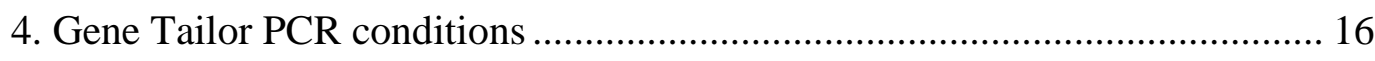

5. Affinity Binding Buffer Solutions .................................................................. 31

6. Between chain hydrogen bonds for the Head-to-head Symmdock \#3 dimer based on I-Tasser model \#1

7. Between chain hydrogen bonds for the Head-to-head Symmdock \#4 dimer based on I-Tasser model \#2 


\section{LIST OF FIGURES}

Figure

PAGE

1. Plasmid map of pGEX-rPSP ......................................................................... 13

2. Crosslinking Parotid Secretory Granules with Formaldehyde........................ 22

3. $\mathrm{Bst}^{3}$ Crosslinking of Parotid Granule Proteins............................................ 24

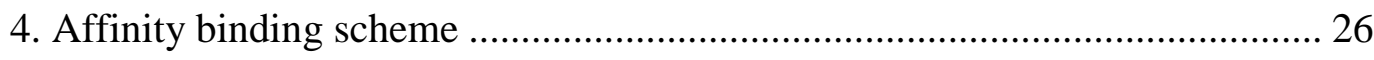

5. Bacterial Lysate PSP Proteins ............................................................ 27

6. Reticulocyte Lysate PSP proteins ...................................................... 28

7. Affinity binding of GST-PSP vs GST with

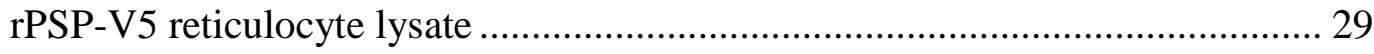

8. Affinity Binding with Various Buffers ...................................................... 32

9. Chloramphenicol acetyl-transferase (CAT) does not bind PSP.................... 35

10. Affinity binding of Human PSP ....................................................... 37

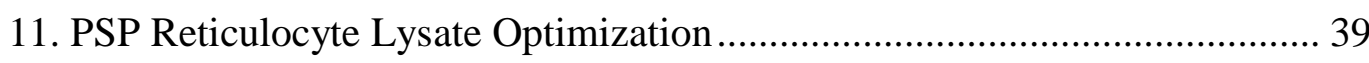

12. Line Graph of GST-PSP binding vs GST Binding ................................ 40

13. Percent rPSP-V5 bound to GST-PSP in Affinity binding ......................... 41

14. Bar Graph GST-PSP vs GST Percent Bound ......................................... 42

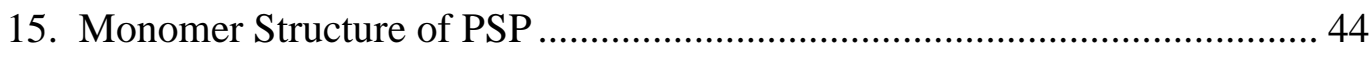

16. I-tasser PSP monomer models ....................................................... 45

17. Symmdock prediction of stacked PSP dimer based off of I-tasser PSP monomer structure ....................................................... 47

18A. Symmdock dimer predictions based on I-Tasser model \#1 ..................... 48 
18B. Symmdock dimer prediction based on I-Tasser model \#2 ....................... 49

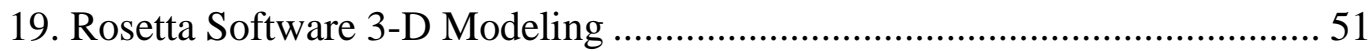

20. Juvenile Hormone Binding-Protein (JHBP) dimer .................................. 53

21. Computer analysis of the representative

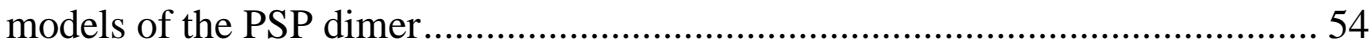

22. PSP Protein Mutants and Truncations .................................................... 56

23. Clones for rPSPdss mutants to test the stacked dimer model ...................... 57

24. Affinity binding with PSP mutants testing

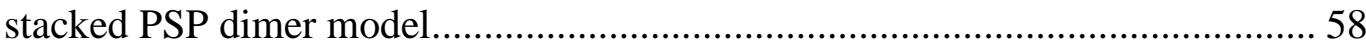

25. Hydrogen bond modeling in the PSP head to head dimer .......................... 59

26. Testing the head-to-head PSP dimer model........................................... 60

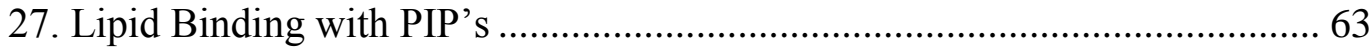

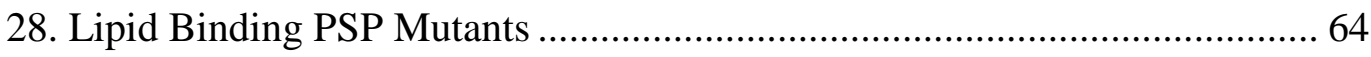

29. Results of Lipid Binding of PSP Mutants to PI $(3,4) \mathrm{P} 2$............................. 65 


\section{INTRODUCTION}

Salivary glands are an essential component to oral health [1]. There are three major salivary glands present bilaterally: submandibular, sublingual and parotid. They function to secrete saliva, which plays an important role in lubrication, buffering, remineralization, and digestion. The parotid gland is the largest of the three major salivary glands and has some unique properties as compared to the other glands. Approximately $60-65 \%$ of total saliva is produced by the parotid, $20-30 \%$ by the submandibular and $2-5 \%$ by the sublingual glands [2]. The parotid glands are purely serous and their secretion is watery and albuminous. The submandibular and sublingual glands are composed of mixed serous and mucous acini, and their secretions are thicker. Majority of our daily saliva comes from the parotid gland, which is imperative to daily human life and function. The content of the secretions of the parotid gland are amylase, Parotid Secretory Protein (PSP) and proline-rich proteins. All of these secretions possess antibacterial properties and are essential in host defense. If this gland is damaged, these proteins are lost as well as their functions.

Individuals that have reduced salivary output experience oral dysfunction with normal daily activities such as speech, mastication, swallowing, taste and halitosis [3]. Decreased amounts of salivary flow can affect soft tissues leading to: epithelial atrophy, ulcerations and soreness, mucositis, and iatrogenic trauma [4]. In addition to these soft tissue changes, studies have shown hyposalivation can create suitable environments for the growth of many oral microorganisms [5]. This can lead to increased risks of 
secondary bacterial, fungal or viral infections. Hard tissue complications can also result from low salivary flow. With decreased salivary flow, teeth are susceptible to fractures, dental caries and have an increased risk of microbial growth. A number of studies have shown the risks associated with losing salivary function. One study showed the number of decayed as well as decayed and filled root surfaces correlates with salivary microbial counts [6]. If saliva is more abundant there will be less decay as opposed to less saliva in which there would be more microbial counts and higher risk of caries. In addition to decay, prosthetic restorations can be quite challenging. Patients will lower amounts of saliva, that have difficulty combating infections often have issues tolerating partials and dentures due to dryness in the oral cavity. This hyposalivation can create issues beyond the oral cavity, including esophageal dysfunction and aspiration pneumonia [7-9].

Salivary glands can be damaged in a multitude of ways. More than 55,000 Americans will develop cancer of the head and neck (most of which is preventable) this year; nearly 13,000 of them will die from it while the others live the rest of their lives trying to cope with the complications that arise from the treatments they receive. The oral cavity is highly susceptible to direct and indirect toxic effects of cancer chemotherapy and ionizing radiation [10]. This risk results from multiple factors, including high rates of cellular turnover for the lining mucosa, a diverse and complex microflora, and trauma to oral tissues during normal oral function [11]. Some oral complications of radiotherapy in the head and neck region are mucositis, loss of taste, osteoradionecrosis, radiation caries, and xerostomia [12]. Salivary glands have slow turnover rates of their cells and theoretically should be relatively radio-resistant [12]. However, studies show a single 
radiation exposure of as low as $2.5 \mathrm{~Gy}$ to the head and neck region of rats can cause significant long-term alterations in salivary gland function.

For radiation patients, mucositis and taste loss is reversible, however xerostomia (dry mouth) related to damage from radiation exposure is irreversible. This symptom is caused by a decreased lubrication in the oral cavity, which is the result of radiation damage to salivary glands. During radiation the glandular tissue changes composition and is gone once destroyed. Research has shown that the amount of exposure a salivary gland has to radiation correlates with the amount of tissue damage seen. In a post mortem human study done by Dreyer et al. [13] they assessed that in the lower dose range $(<30$ Gy), damage is reversible to a certain extent, however, after a total dose of (>75 Gy) extensive degeneration of acini is found along with inflammation and fibrosis of the interstitium. Serous acinar cells appear to be more readily affected by irradiation than mucous acinar cells and ductal cells. There have been numerous studies using the rat model that show within three days after irradiation with a single dose of 15 Gy of x-rays, a decreased salivary flow of nearly $50 \%$ can be observed [14]. Copper et al. observed four phases in the radiation-induced loss of salivary gland function. The first phase (0-10 days) is characterized by a rapid decline in flow rate without changes in amylase secretion or acinar cell number. The second phase (10-60 days) includes a decrease in amylase secretion as well as acinar cell number which plateaus in the third stage. The fourth stage (120-240 days) shows further deterioration of gland function with very poor tissue morphology despite an increase in acinar cell number[15]. With both early and late responses to radiation, salivary gland tissue is the most frequently occurring side effect of head and neck radiation. This serious side effect often times lead to other side 
effects, which severely decrease a patient's quality of life. In addition to a decrease in the quantity of saliva during radiotherapy, an unpleasant change in the consistency and composition of a patient's saliva also occurs. After radiation, patient's saliva gets ropelike and viscous, leading to a decreased $\mathrm{pH}$ and buffering capacity. This results in altered immune and antibacterial properties that are necessary for good oral health. There is a gradual oral flora shift seen in cancer patients due to acidogenic, cariogenic microorganisms that lead to increased risk of caries, periodontal disease as well as other oral manifestations. A systematic review was done in the literature to update current understanding of how cancer therapies impact patient dental care. In the review of 64 papers, the weighted overall prevalence of dental caries was $28.1 \%$. They found that patients who were post-radiotherapy had the highest decayed, missing and filled teeth (DMFT) index of 17.1 vs healthy controls of $4.4[16,17]$. The review also noted a higher presence of severe gingivitis than in normal healthy individuals.

Salivary research has shown head and neck cancer radiation will decrease parotid gland volume and wipe out essential functions of the parotid salivary gland as well as alter parotid saliva consistency [18]. Treatment focus should be on optimized/new approaches to further reduce the dose to the parotids, and particularly submandibular and minor salivary glands, as these glands are major contributors to moistening of oral tissues [19]. All of these changes drastically change a patient's quality of life, their ability to function and further prevent oral diseases.

While the affects of radiotherapy for head and neck cancer greatly diminish saliva production, it does not come close to the number of people affected by Sjogren's Syndrome. Sjogren's is an autoimmune disorder in which immune cells attack and 
destroy the glands that produce tears and saliva. This disorder affects 1-4 million people in the US, most of which are more than 40 years old at the time of diagnosis. Women are 9 times more likely to have Sjogren's syndrome than men. The hallmarks of this disorder are dry mouth and eyes. There is no cure for Sjogren's and treatment is based on patient's symptoms and quality of life. The severity of symptoms can vary from patient to patient. Often times Sjogren's patients suffer from the same complications as head and neck cancer patients such as recurrent mouth infections, swollen parotid glands, hoarseness, difficulty swallowing and eating, as well as increased risk of caries and other dental issues.

The goals of research on disorders such as Sjogren's syndrome focus on increasing knowledge and understanding of the disorder, improving diagnostic techniques, and finding ways to treat, prevent and cure the disease. The United States Department of Health and Human Services has begun tracking the number of people affected by salivary gland dysfunction [http://www.ninds.nih.gov/disorders/sjogrens/sjogrens.htm]. National organizations are coming together to fund research programs specifically looking at the functional restoration of salivary glands. The goal of this funding is to encourage multidisciplinary studies focusing on restoring salivary gland function, including repair and regeneration of the host salivary gland, or replacement of a disease or damaged gland with a bioengineered gland.

This current wave of research is looking at clinically and physiologically relevant treatments such as gene therapy to help patients not just cope with their complications but to regain function. In order for gene therapy to be successful we need to understand the 
complex network of protein trafficking and secretion pathways in salivary gland cells. Once we have a firm understanding of protein sorting we can then design therapeutic proteins to fight systemic diseases [20].

\section{MECHANISM OF PAROTID GLAND SECRETION}

The parotid gland secretes copious amounts of specific proteins into the saliva. Salivary proteins include amylase, PSP, and Proline-Rich Proteins, and less abundant proteins such as histatin and statherin [21]. These three proteins are the most abundant luminal cargo proteins within the secretory granule. These proteins move through the trans-Golgi network along with hundreds of other proteins that are sorted into the correct pathway for secretion. Acinar cells, the functional unit of the parotid gland function as the regulatory center for synthesis and secretion of salivary proteins such as amylase and PSP. These secretory proteins are stored within secretory granules and participate in several pathways in the cell when induced by external and internal signals.

Due to the popularity of genetic engineering, salivary glands are becoming a target site for transgenes to be introduced to patients [22]. Secretion and sorting of proteins in the parotid, as with other exocrine cells, includes the (1) major regulated pathway, (2) minor regulated pathway, (3) apical and basolateral constitutive secretory pathways, and (4) constitutive-like secretory pathway [22]. Researchers are working on defining molecular interactions that affect sorting pathways in exocrine cells; however all the known mechanisms are not present in other cell types. In neuroendocrine and endocrine cells the $\mathrm{pH}$ of the secretory granules decrease during maturation from 6.2 at the trans Golgi network (TGN) to 5.5-5.0 in the mature granule [22-24]. This acidic environment 
is important for correct sorting and protein aggregation of certain cells [24]. In the parotid gland, the $\mathrm{pH}$ of the acinar cell granule increases from about $\mathrm{pH} 6.2$ at the TGN to 6.8 or higher after maturation [25]. Furthermore, granule cargo proteins from parotid acinar cells (amylase and PSP) are unable to aggregate even in the presence of $\mathrm{Ca}++$ and low $\mathrm{pH}$, whereas pancreatic exocrine granule proteins (used as a control) aggregate in a fashion similar to endocrine cells [26]. This indicates that sorting of amylase and PSP in the parotid gland have some differences from endocrine cells that need to be studied.

The parotid gland is an important study model in understanding regulation of secretory proteins. Out of all of the sorting mechanisms, parotid acinar cells have several regulated secretory pathways that secrete proteins in response to extracellular stimulation. The Regulated Secretion pathway is the main way in which secretory granules in exocrine cells are secreted, especially PSP. They make up $80-90 \%$ of total protein secretion from parotid acinar cells [27]. This pathway targets the cargo proteins to the apical surface and into the oral cavity. Basal secretion is the other form of secretion that responds to extracellular stimulation but does not depend on it strongly. This secretion represents resting secretion of saliva between meals and the exocytosis from the minor regulated secretory pathway.

Unlike the regulated secretion pathway, Constitutive Secretion represents the small continuous output of salivary proteins in the absence of stimulation. Analysis of unstimulated secretion from parotid tissue has identified three phases of unstimulated protein secretion [28]. The first phase constitutes proteins that appear to differ from granule proteins and may represent the constitutive secretory pathways in acinar cells or constitutive secretion from other cell types in the tissue. It is likely that the constitutive 
secretory pathway exists for the delivery of basolateral plasma membrane proteins and extracellular matrix components as well as being the only secretion that does not originate in the secretory granules but in the trans-Golgi network and ultimately ends up in the circulation. Much of the research in the past has been on apical secretion, however, learning about the basolateral secretory pathways in acinar cells might be helpful in our venture for discovering a cure for Sjogrens or limiting the devastating loss of parotid function in head and neck cancer patients. The goal of salivary glands producing and secreting therapeutic proteins from transgenes are vital for any of these clinical applications to exist.

\section{PAROTID SECRETORY PROTEIN}

Parotid Secretory Protein (PSP) is a protein secreted from the parotid and sublingual salivary glands. PSP is known to have anti-bacterial, anti-viral, and antiinflammatory properties. PSP activity is of interest to compare to related proteins. Following the newly developed nomenclature [29] , rat PSP/BPIFA2E is a member of the PLUNCA subfamily of the BPI-fold superfamily [30]. The PLUNC locus on chromosome 20q11.21 has evolved through a series of gene duplication events ([31] , [32]). Analysis of these proteins has shown that their predicted structures are similar to that of lipopolysacharride (LPS)-binding protein (LBP) and bactericidal/permeabilityincreasing protein (BPI), two essentially antagonistic, mammalian proteins critical in the mediation of signals from LPS. This similarity has led to speculation that the PLUNC family also have a host defense function. Whereas BPI is a product of inflammatory cells [33] and LBP is primarily produced within the liver [34], studies have previously shown that SPLUNC1 is most prominently expressed in the nose, salivary glands and upper 
respiratory tract [35]. The sites of SPLUNC1 expression correspond to locations where significant pathogenic loads are encountered and where bacterial sensing and/or neutralizing proteins might be required.

Parotid Secretory Protein is one of the most abundant salivary proteins. As a result of research done on PSP we know that it is important for sorting pathways in secretory granules of the parotid cell [27]. However, PSP function and structure is not known. Therefore, by understanding the structure of PSP, the mechanism of sorting of PSP can be understood .

Studies by Venkatesh et al. conclude that amylase and PSP sorting have important differences [26]. Western blot analysis was done with independent purified samples and confirmed that PSP selectively bound to granule membranes, unlike amylase and ProlineRich Protein (PRP)[36]. When exogenous PSP was tested with digested granule membranes it still bound effectively, indicating that PSP does not require a protein receptor for binding to the membrane. This was not the case for exogenous amylase that was only found in the unbound fraction, emphasizing the specificity of PSP binding.

The direct trafficking of parotid secretory protein is not well known. However, previous results show both bacterially expressed rat PSP and human PSP synthesized in vitro bind specifically to Phosphatidylinositol $(3,4)$ Bisphosphate [36]. PSP bound to $\mathrm{PI}(3,4) \mathrm{P} 2$ 10-fold stronger than to PtdIns $(3,5) \mathrm{P}_{2}$ or PtdIns(4)P. The ability of PSP to decorate membranes suggests additional functions and may give us more insight as to how PSP is sorted and secreted. Therefore, we want to define all the protein interactions of PSP. The phosphorylated forms of phosphatidylinositol lipids typically function to anchor proteins to specific membranes. It has been found that both human and rat PSP 
bind specifically to $\mathrm{PI}(3,4) \mathrm{P}_{2}$, either in liposome membranes or on lipid-overlay assays [37]. Other experiments suggest that this binding is important for interaction of PSP with secretory granule membranes. The ability of PSP to decorate membranes suggests additional functions, such as anchoring other proteins. However, in order to understand this binding and possible trafficking roles, defining the quaternary structure of PSP is vital. Preliminary crosslinking results suggest PSP may dimerize, which is the basis for this study. In this Masters Research project, one of the goals was to understand PSP quaternary structure. Structural modeling suggests several different dimer possibilities and it is our goal to provide experimental support suggesting whether one model is more likely. The focused hypothesis for this work was that PSP forms a specific dimer as the quarternary structure. My results not only support a head-to-head PSP dimer model, but also indicate that this dimerization is essential for the lipid-binding function of PSP. 


\section{MATERIALS AND METHODS}

\section{CLONE PRODUCTION - GST- FUSION PROTEINS}

In order to study the dimerization of PSP, it was important to produce a glutathione-S-transferase (GST) fusion protein. Fusion proteins are desirable because of the ease of affinity purification without denaturation. Vectors such as pGEX 4T-3 provide chemically induced and highly efficient expression of the GST-tagged recombinant PSP protein. This vector was used in E.coli as a C-terminal fusion with the $26 \mathrm{kDa}$ glutathione-S-transferase protein [38]. Rat PSP (rPSP) cDNA sequence was amplified by standard PCR. The primers used were dssBamPSPFor and rPSPEcoR1Rev (see Table 1 Primer Sequences). The PCR reaction was done using r-PSP-V5-6HispcDNA3.1 as the parent plasmid. The PCR conditions were optimized and samples were run at $95^{\circ}$ for $10: 00$, followed by $\left(94^{\circ}\right.$ for $0: 45,67^{\circ}$ for $0: 45,72^{\circ}$ for $\left.2: 00\right)$, repeated 30 times, $72^{\circ}$ for $10: 00$, and $4^{\circ}$ for infinity.

After PCR was complete, the amplified DNA was analyzed by agarose gel electrophoresis, and purified from the gel using the QIAQuick PCR Purification kit and then the QIAGEN QIAquick Gel Extraction Kit (following the manufacture's protocol). The eluted DNA was digested with EcoRI and BamHI, using a serial digestion, with the first digestion reaction incubating all day, the second overnight. The ligation reaction was incubated over night at $16^{\circ} \mathrm{C}$, then transformed into $\mathrm{DH} 5 \alpha$ cells via heat shock at $42^{\circ}$ for 30 seconds. Cells were rescued in standard Luria Broth (LB) and plated on ampicilan plates for selective growth. Colonies were chosen and 16 were minipreped with Promega 
Wizard Plus SV Minipreps DNA Purification System (Promega Corporation, Madison, WI, USA). Throughout this project the DNA sequences of all clones were confirmed by both restriction enzyme digests and sequencing at the UofL CGeMM DNA Sequencing core before clones were used in experiments.

\section{CONSTRUCTION OF CLONES}

The clones prepared for this work are listed in Table 1 and Figure 1. Each pGEX mutant was designed to express a GST fusion protein. All the clones were DNA sequenced to show correct reading frame and were then transformed into native BL21 competent cells for protein expression.

Table 1: List of the Expression Vector pGEX 4T-3 Clones for studying the dimerization of Parotid Secretory Protein

\begin{tabular}{|l|l|l|l|}
\hline INSERT & TAG & FINAL CLONE & Protein Name \\
\hline $\begin{array}{l}\text { Rat-PSP deleted signal } \\
\text { sequence. }\end{array}$ & None & $\begin{array}{l}\text { rPSPdss-STOP- } \\
\text { pGEX4T-3 }\end{array}$ & GST-dss-rPSP \\
\hline No Insert & None & pGEX4T-3 & GST \\
\hline $\begin{array}{l}\text { Human-PSP deleted signal } \\
\text { sequence }\end{array}$ & None & humPSPdss-pGEX4T-3 & GST-dss-hPSP \\
\hline $\begin{array}{l}\text { Rat-PSP deleted signal } \\
\text { sequence, deleted N } \\
\text { terminal 6 amino acids. }\end{array}$ & None & rPSPdss-SU6-pGEX4T-3 & GST- rPSP-SU6 \\
\hline $\begin{array}{l}\text { Rat-PSP deleted signal } \\
\text { sequence, deleted N } \\
\text { terminal 13 amino acids. }\end{array}$ & None & $\begin{array}{l}\text { rPSPdss-SU13-pGEX4T- } \\
\text { (3) }\end{array}$ & GST- rPSP-SU13 \\
\hline
\end{tabular}


Figure 1: Plasmid map of pGEX-rPSP.

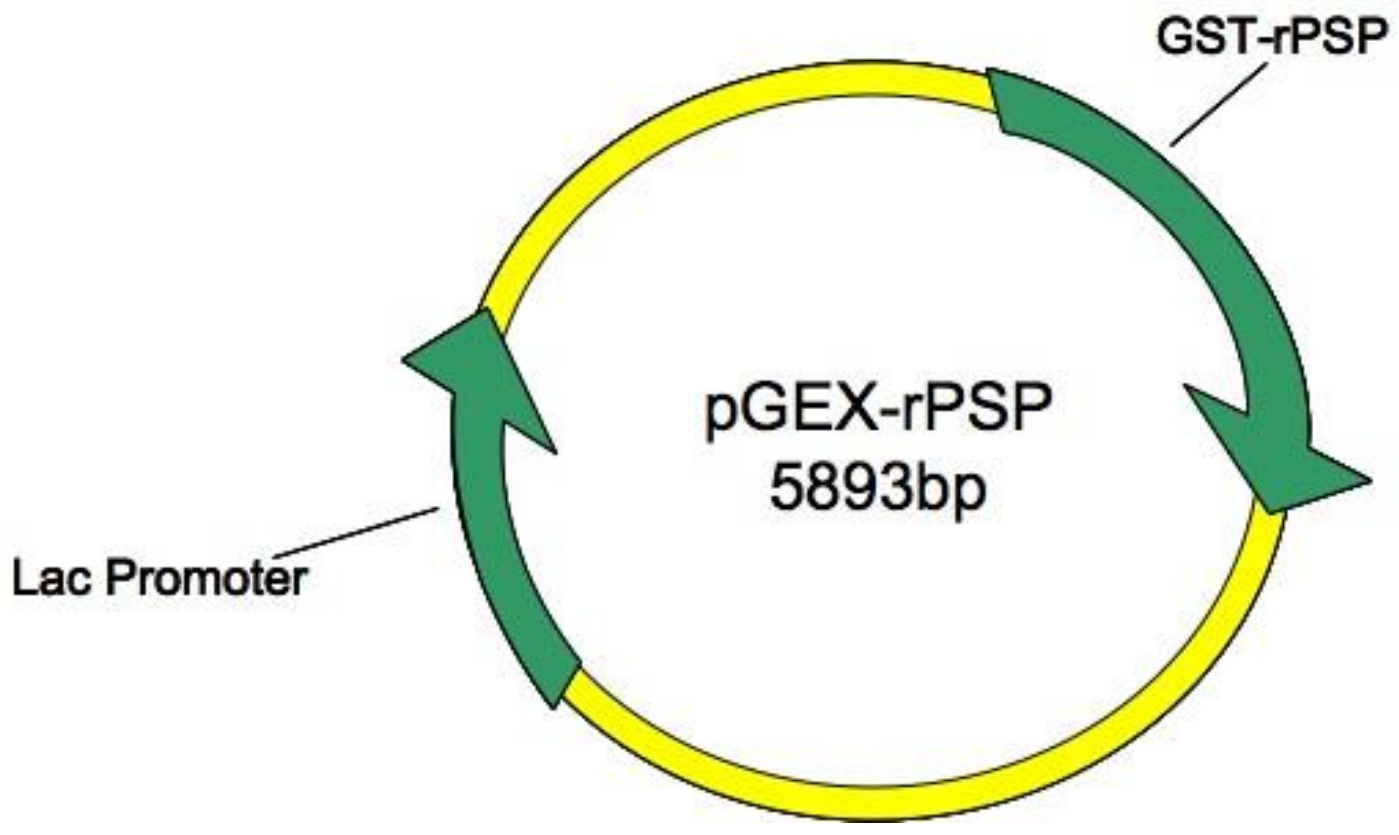

Figure 1: Different PSP cDNA sequences were cloned into the pGEX expression vector. A GST empty vector was also made for a negative control. No V5 epitope tags were used in this cloning process. 
The mutants expressed in a reticulocyte lysate are listed in Table 2.

Table 2: Expression Vector pcDNA 6.2 clones for studying the expression and dimerization of Parotid Secretory Protein

\begin{tabular}{|c|c|c|c|}
\hline INSERT & TAG & FINAL CLONE & Protein Name \\
\hline $\begin{array}{l}\text { rat-PSPdss-V5[13], full } \\
236 \text { aa PSP, no attB }\end{array}$ & V5[13] & $\begin{array}{l}\text { rPSPdss-V5[13]- } \\
\text { pcDNA6.2 }\end{array}$ & rPSPdss-V5 \\
\hline $\begin{array}{l}\text { C-terminus V5 tag, 9aa } \\
\text { version, rat-PSPdss, stop } \\
\text { codon to prevent reading } \\
\text { into attB and V5[14] } \\
\text { sequence }\end{array}$ & V5[9] & $\begin{array}{l}\text { M-V5[9]-rPSPdss- } \\
\text { STOP-pcDNA6.2 }\end{array}$ & rPSPdss-V5 \\
\hline $\begin{array}{l}\text { rat-PSP-includes signal } \\
\text { sequence, stops after } 107 \\
\text { amino acids, includes attB } \\
\text { and V5[14] from vector }\end{array}$ & V5[14] & $\begin{array}{l}\text { rPSP-3174- } \\
\text { pcDNA6.2 }\end{array}$ & rPSP-317 $\square$ \\
\hline $\begin{array}{l}\text { rat-PSPdss, stops after } 151 \\
\text { amino acids, includes attB } \\
\text { and V5[14] from vector }\end{array}$ & V5[14] & $\begin{array}{l}\text { rPSPdss-435 } \Delta- \\
\text { pcDNA6.2 }\end{array}$ & rPSPdss-435 $\square$ \\
\hline $\begin{array}{l}\text { rat-PSPdss, stops after } \\
212 \text { amino acids, includes } \\
\text { attB and V5[14] from vector }\end{array}$ & V5[14] & $\begin{array}{l}\text { rPSPdss-636 } \\
\text { pcDNA6.2 }\end{array}$ & rPSPdss-636 $\square$ \\
\hline $\begin{array}{l}\text { Chloramphenicol acetyl } \\
\text { transferase }\end{array}$ & V5[14] & $\begin{array}{l}\text { pcDNA6.2/V5/GW- } \\
\text { CAT provided by } \\
\text { Invitrogen as a } \\
\text { control. }\end{array}$ & CAT-V5 \\
\hline $\begin{array}{l}\text { rat-PSP deleting the } \mathrm{N} \\
\text { terminus } 39 \text { amino acids, } \\
\text { directly linked to the V5[13] } \\
\text { tag, no attB sequence. }\end{array}$ & V5[13] & $\begin{array}{l}\text { rPSP-39ATG- } \\
\text { V5[13]-pcDNA6.2 }\end{array}$ & 39ATG-PSP-V5 \\
\hline $\begin{array}{l}\text { rat-PSP deleting the } \mathrm{N} \\
\text { terminus } 55 \text { amino acids, } \\
\text { directly linked to the V5[13] } \\
\text { tag, no attB sequence. }\end{array}$ & V5[13] & $\begin{array}{l}\text { rPSP-55ATG- } \\
\text { V5[13]-pcDNA6.2 }\end{array}$ & 55ATG-PSP-V5 \\
\hline $\begin{array}{l}\text { C-terminus V5[9] tag, rat- } \\
\text { PSP deleting the C terminus } \\
55 \text { amino acids, and the } \mathrm{N} \\
\text { terminus } 13 \text { amino acids. } \\
\text { Stop code inserted to } \\
\text { prevent reading into the } \\
\text { vector attB and V5[14] } \\
\text { region }\end{array}$ & $\begin{array}{l}\mathrm{C} \\
\text { terminus } \\
\mathrm{V} 5[9]\end{array}$ & $\begin{array}{l}\text { M-V5[9]-55ATG- } \\
\text { PSP-SU13-STOP- } \\
\text { pcDNA6.2 }\end{array}$ & $\begin{array}{l}\text { M(V5)-55-ATG- } \\
\text { PSP-SU13 }\end{array}$ \\
\hline
\end{tabular}




\begin{tabular}{|c|c|c|c|}
\hline $\begin{array}{l}\text { C-terminus V5[9] tag, rat- } \\
\text { PSP deleting the N terminus } \\
55 \text { amino acids and the C } \\
\text { terminus } 6 \text { amino acids. } \\
\text { Stop code inserted to } \\
\text { prevent reading into the } \\
\text { vector attB and V5[14] } \\
\text { region }\end{array}$ & $\begin{array}{l}\mathrm{C} \\
\text { terminus } \\
\text { V5[9] }\end{array}$ & $\begin{array}{l}\text { M-V5[9]-55ATG- } \\
\text { PSP-SU6-STOP- } \\
\text { pcDNA6.2 }\end{array}$ & $\begin{array}{l}\text { M(V5)-55-ATG- } \\
\text { PSP-SU6 }\end{array}$ \\
\hline
\end{tabular}

TOPO VECTOR CLONING

Invitrogen $\mathrm{TOPO} \circledast$ cloning was used to make clones for studying the

dimerization of PSP. The main element of TOPO is the enzyme DNA topoisomerase I, which functions both as a restriction enzyme and a ligase. Its biological role is to cleave and rejoin DNA during replication. Using PCR technology, the gene of interest (PSP) was fused with different epitope tags and cloned into a pcDNA 6.2 Gateway Directional TOPO vector. PCR reactions were done using Platinum PCR SuperMix High Fidelity from Invitrogen Corporation Carlsbad, CA. PCR conditions were optimized and are shown in Table 3:

Table 3: TOPO Vector PCR Conditions

\begin{tabular}{|c|c|c|}
\hline Temperature & Time (min) & Cycle Repeated \\
\hline 95 & $6: 00$ & One time \\
\hline $94^{\circ}$ & $0: 30$ & \multirow{3}{*}{10 times } \\
\hline $60^{\circ}$ & $0: 30$ & \\
\hline $72^{\circ}$ & $1: 45$ & \\
\hline $94^{\circ}$ & $0: 30$ & \multirow{3}{*}{10 times } \\
\hline $62^{\circ}$ & $0: 30$ & \\
\hline $72^{\circ}$ & $1: 45$ & \\
\hline $72^{\circ}$ & 10:00 & One time \\
\hline $4^{\circ}$ & $\infty$ & $\infty$ \\
\hline
\end{tabular}

The PCR amplification was confirmed by agarose gel electrophoresis. PCR fragment was purified via low melt gel and then the QIAQuick PCR Gel extraction and purification kit, 
resulting DNA was eluted with water, quantitated and set to ligate in a TOPO ligation reaction. Resultant ligation mix was transformed into TOP 10 DH5- $\alpha$. Minipreps were done on 11 colonies and several were confirmed by CORE Center at the University of Louisville. This DNA plasmid was then propagated in E. coli. These clones where then subcloned into the prokaryotic expression plasmids pGEX 4T-3 from GE Healthcare Bio-Sciences Corp (Piscataway, $\mathrm{NJ}$ ) so as to maintain reading frames downstream to the inducible LacZ promoter, and adjacent to a fragment of the recombinant glutathione Stransferase gene. GST-PSP fusion proteins were prepared from large scale bacterial cultures.

\section{GENE TAILOR MUTAGENESIS}

The GeneTailor Site-Directed Mutagenesis System by Invitrogen Corporation Carlsbad, CA was used as the method to produce highly efficient in vitro site-directed mutagenesis. This system can generate base substitutions, deletions, or insertions of up to 21 nucleotides in DNA plasmids of up to $8 \mathrm{~kb}$ from any source with no specialized vectors, host strains, or restriction sites required. This system was used in the production of the point mutant PSP clones to study the hydrogen bonds within PSP. First the methylation reaction was done. For the mutagenesis reaction Platinum ${ }^{\circledR} P f x$ DNA Polymerase was used with $2 \mu 1$ of methylation mixture per $50 \mu 1$ of mutagenesis reaction was used. Parameters for the PCR were as in Table 4:

\section{Table 4: Gene Tailor PCR conditions}

\begin{tabular}{|c|c|c|}
\hline Temperature & Time (min) & Cycle Repeated \\
\hline $94^{\circ}$ & $2: 00$ & One time \\
\hline $94^{\circ}$ & $0: 30$ & \multirow{2}{*}{20 times } \\
\hline $55^{\circ}$ & $0: 30$ & \multirow{2}{*}{20 . } \\
\hline $68^{\circ}$ & $1: 00 / \mathrm{kb}$ DNA & \\
\hline
\end{tabular}




\begin{tabular}{|c|c|c|}
\hline $68^{\circ}$ & $10: 00$ & One time \\
\hline $4^{\circ}$ & $\infty$ & $\infty$ \\
\hline
\end{tabular}

After the reaction, $10-20 \mu l$ of the product was analyzed on a $1 \%$ agarose gel.

\section{PURIFICATION OF FUSION PROTEIN}

Fresh LB culture (200 mL) was inoculated with the BL21DE3 cells harboring the GST-rPSP and the negative control GST (No PSP) clones and incubated at $37^{\circ} \mathrm{C}$ overnight. $15 \mathrm{~mL}$ of overnight culture was inoculated in fresh $100 \mathrm{~mL}$ LB medium and incubated until the absorbance at $600 \mathrm{~nm}$ reached 0.8 . Protein expression was induced by $0.1 \mathrm{mM}$ IPTG and after two hours of incubation, cells were harvested by centrifugation at $3750 \mathrm{rpm}$ for 20 minutes. The pellet was washed and resuspended in $5 \mathrm{~mL}$ of PBS containing $1 \mathrm{mM}$ PMSF and protease inhibitors. The Branson 150 Sonicator was used to disrupt the bacterial cells. Cells were sonicated for 10 seconds then put on ice for 10 seconds and repeated 4 times. The sonicated lysate was then centrifuged and bacterial supernatant was aliquoted into fresh $1.5 \mathrm{~mL}$ microcentrifuge tubes and stored at $-80^{\circ} \mathrm{C}$. Protein expression was quantified using biorad assay.

\section{PROTEIN ASSAY}

Bio-Rad Laboratories, Hercules, CA protein assays were used to test the protein production of each bacterial lysate. A BSA serial dilution was used to create a standard curve ranging from $120 \mu \mathrm{g} / \mathrm{ml}$ to $0.1 \mu \mathrm{g} / \mathrm{ml}$. Each dilution had $10 \%$ sonication buffer to equalize all dilutions. Each fusion protein was diluted with the same dilution equivalent of maintaining a $10 \%$ sonication buffer solution. On a 96 well plate, triplicate aliquots were done with both BSA dilutions and GST-fusion proteins. The plate was read on a 
Victor 3 spectrophotometer. The readings were then analyzed using Microsoft Excel spreadsheet.

\section{ISOLATION OF PAROTID SECREORY GRANULES}

Parotid Secretory granules were purified from rat parotid glands by differential centrifugation. Rat parotid glands were homogenized in $0.285 \mathrm{mM}$ sucrose $-20 \mathrm{mM}$ HEPES and then suspension centrifuged at $2020 \mathrm{x}$ g. All centrifugations were preformed for 10 minutes. The supernatant was collected and centrifuged at $2884 \mathrm{x} \mathrm{g}$. The pellet obtained was resuspended in sucrose buffer and centrifuged $1884 \mathrm{x}$ g followed by centrifugation of the obtained supernatant at $2884 \mathrm{x}$ g to pellet the secretory granules. The granules were suspended in water,lysed by freeze-thaw, the suspension centrifuged at $18,000 \mathrm{x} \mathrm{g}$ and soluble cargo proteins separated from the granule membranes. The soluble fraction was used for crosslinking studies with $\mathrm{Bst}^{3}$ (Thermo Fisher Scientific Inc. Rockford, IL. Crosslinked products were analyzed by SDS-PAGE and western blots for amylase and PSP.

\section{CROSSLINKING METHOD}

The crosslinking procedure started with isolation of rat parotid granules, suspended in sucrose-HEPES [500 $\mu 1$ ]. Then $1.41 \mu 1$ of 37\% Formaldehyde was added to the tubes and incubated at room temperature for 2 minutes and 10 minutes. The control granules did not get formaldehyde. Next, $3.4 \mu \mathrm{l}$ of $2 \mathrm{M}$ glycine $(.75 \mathrm{~g}$ in $5 \mathrm{mls})$ was added to the tube and the reaction was quenched for 5 minutes. The tubes were then centrifuged at $3000 \mathrm{G}$ for 10 minutes to bring down the granules. The supernatant was taken out and the granules were washed in $50 \mu \mathrm{l}$ of sucrose-HEPES. Centrifugation was repeated for 10 minutes and the supernatant was removed. Resuspension of the pellet was preformed in 
$50 \mu 1$ of sucrose-HEPES. An aliquote of $25 \mu 1$ of sample was added to $25 \mu 1$ of gel loading buffer with or without 2-Mercaptoethanol ( $\beta \mathrm{ME})$ to corresponding tubes. All samples were heated in the hood for 5 minutes and then loaded onto SDS-PAGE and transferred by western blot and analyzed.

\section{AFFINTY BINDING EXPERIMENT PROTOCOL}

Glutathione sepharose 4B was obtained from GE Healthcare. The glutathione slurry was washed with cold, sterile, PBS, then centrifuged at $1000 \mathrm{x} g$ for one minute. This was repeated a total of three times. The sonicated GST-fusion proteins from the $-80^{\circ}$ freezer were thawed and equal amounts of protein (via BioRAD assay results) were place on $75 \mu \mathrm{l}$ of glutathione sepharose resin. GST-fusion proteins were then incubated with the resin for 1 hour at $4^{\circ} \mathrm{C}$ with mild agitation. After the incubation of the sonicated bacterial lysates on the resin it was washed six times with cold sterile PBS and spun at $1000 \mathrm{x} g$ for one minute. Resin was then resuspended with $500 \mu \mathrm{l}$ of binding buffer (PBS). Then using the Promega TNT Translational Kit rPSP-V5 protein was synthesized and incubated with the immobilized GST-PSP fusion protein. Reticulocyte lysates were incubated for 90 minutes with agitation at room temperature. After binding was allowed to occur the resin beads were spun down and washed with PBS four times with binding buffer. $50 \mu 1$ of $4 \mathrm{X}$ SDS-PAGE sample buffer was then added to the reaction tube and samples were boiled for five minutes. The supernatant was then loaded on to Invitrogen NuPAGE $4-12 \%$ Bis-Tris Gels $1.5 \mathrm{~mm} \times 10$ well gel. The gel was run at constant 45 mAmps. Bound proteins were then analyzed by western blots and probed with Invitrogen anti-V5 antibodies. These antibodies detected the PSP-V5 protein not the GST-PSP protein. Quantitation was done on the Kodak Imager using the SuperSignal West Pico 
Chemiluminescent substrate from Thermo Scientific. The intensity of the bands or regions of binding were quantitated and compared from straight protein signal. COMPUTER MODELING OF QUATERNARY STRUCTURE

The computer modeling program I-Tasser

(http://zhanglab.ccmb.med.umich.edu/I-TASSER/) was used to model the PSP monomer structure. I-Tasser iteratively threads the PSP sequence through segmental comparisons to the large number of locally related gene sequences, and segments are compared to the Protein Structure Data Base (PDB) to identify optimal folds, and reassembled.

SymmDock (http://bioinfo3d.cs.tau.ac.il/SymmDock/symmdock.html) was then used to identify two classes of significant PSP dimer models. SymmDock is an algorithm for prediction of complexes with $C_{n}$ symmetry by geometry based docking. For our PSP dimer models we see the $\mathrm{C}$-terminal (or carboxy-terminal) tab crosses the line of symmetry and interacts with the opposite chain N-terminal alpha helix.

Rosetta 3.4 docking protocol (https://www.rosettacommons.org/manuals/archive/rosetta3.4_user_guide/index.html) was used as another protein predictor model. This program does not make any assumptions on symmetry. With this program, it came up with the exact same head-tohead dimer model strengthening our interest in explore this interaction.

\section{PROTEIN-LIPID BINDING}

A standard overlay protocol was used for testing protein binding to lipids. The first step was to bind lipids to the nitrocellulose membranes. Each membrane was spotted with 100 pmoles of phospatidylinositol (PtdIns) and with two forms of phosphatidylinositol bisphosphate; PtdIns(3,4)P2 and PtdIns(3,5)P2. Secondly, the 
nitrocellulose membranes were blocked with $1 \%(\mathrm{w} / \mathrm{v})$ non-fat milk in PBST [50 mM phosphate buffer, $150 \mathrm{mM}$ sodium chloride $(\mathrm{NaCl})$, and $0.1 \%(\mathrm{w} / \mathrm{v})$ Tween-20] for 1 hour [39]. Next the PSP-V5 reticulocyte lysate protein was translated and incubated on the blocked membranes for 1 hour at room temperature. The membranes were washed thoroughly with PBST. The bound protein on the nitrocellulose membranes was detected by probing with Mouse monoclonal pk-1V5 primary antibody, and then a Goat-Anti Mouse-HRP secondary antibody. The antibody signal was then picked up by a tetramenthylbenzidine (TMB) substrate kit (Thermo Scientific, Rockford, IL, USA) on a Kodak Imager [36]. 


\section{RESULTS}

\section{FORMALDEHYDE CROSSLINKING WITH PAROTID SECRETORY GRANULES}

The goal of this experiment was to examine if native parotid secretory granules crosslink to other proteins. Using the crosslinking protocol from the method section, results showed native PSP protein crosslinked into a $45 \mathrm{kDa}$ complex, twice the size of PSP. The negative controls showed no crosslinking of PSP protein. Concluding native PSP may form dimers to one another.

Figure 2: Crosslinking Parotid Secretory Granules with Formaldehyde.

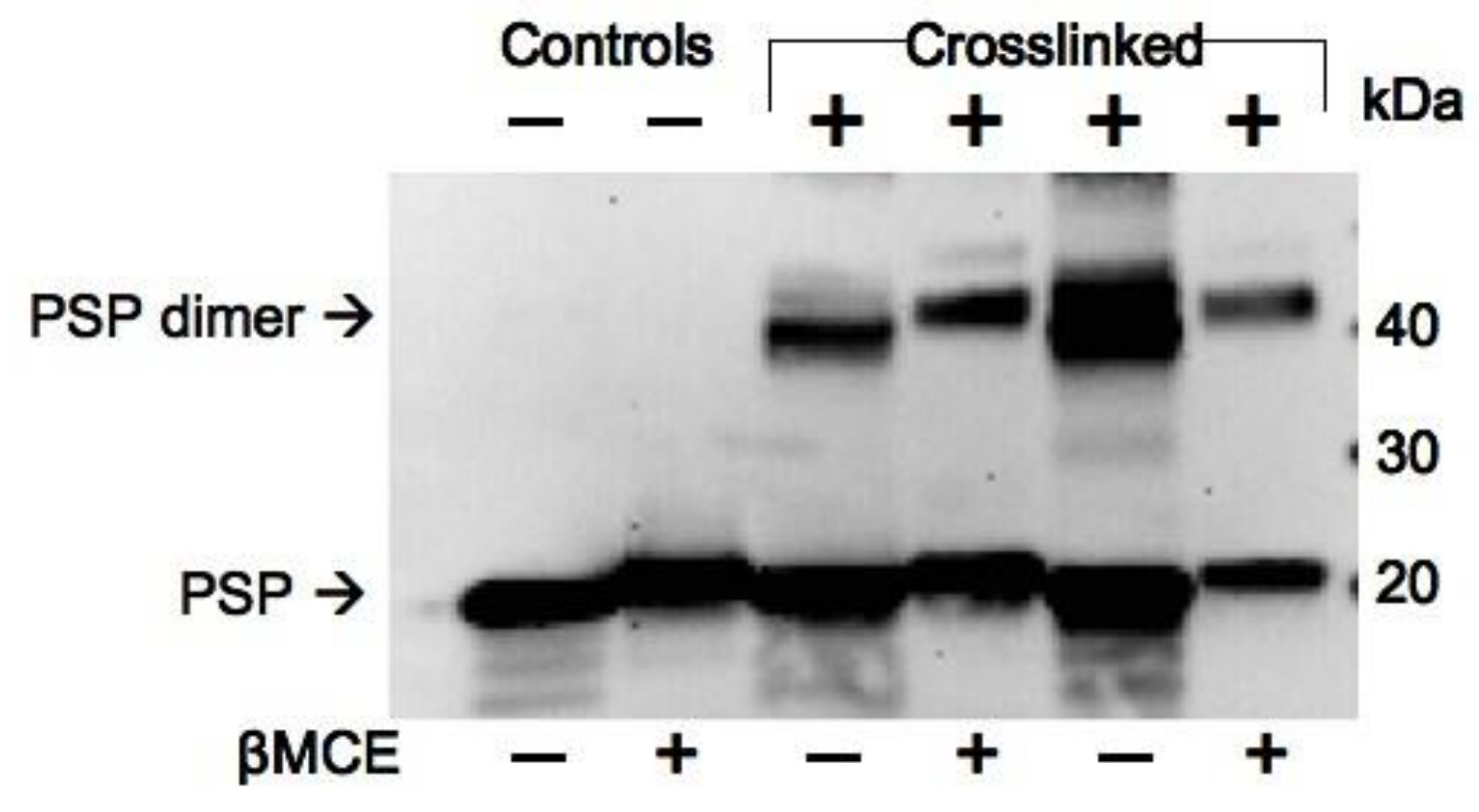

Figure 2: Parotid secretory granules were isolated and cross-linked with formaldehyde.

SDS-PAGE and western blots with antibodies specific for PSP were used to identify crosslinked complexes. The experiment showed PSP is crosslinked into a $45 \mathrm{kDa}$ complex, twice the size of PSP, suggesting a dimer. 
Additional PSP crosslinking studies were done testing the possible dimer formation with amylase. A different crosslinker $\mathrm{Bst}^{3}$ was used to compare the two cargo proteins. SDS-PAGE and western blots with antibodies specific for either PSP or amylase were used to identify crosslinked complexes. The cargo protein amylase did not crosslink at either concentration tested. The lack of complex formation by amylase shows that there is at least some level of specificity for formation of the PSP complex. I observed a 45 $\mathrm{kDa}$ PSP complex at $0.025 \mathrm{mM} \mathrm{Bst}^{3}$, as compared to published methods using $0.1-1.0$ $\mathrm{mM} \mathrm{Bst}^{3}[40,41]$. Crosslinking at low reagent concentrations is consistent with the presence of a stable complex. We found native PSP crosslinked into a 45kDa complex, twice the size of PSP, suggesting a dimer. Although we have a good indication of possible dimerization, a more defined system is needed, therefore we moved to affinity binding studies in order to quantitate binding. 
Figure 3: $\mathrm{Bst}^{3}$ Crosslinking of Parotid Granule Proteins.

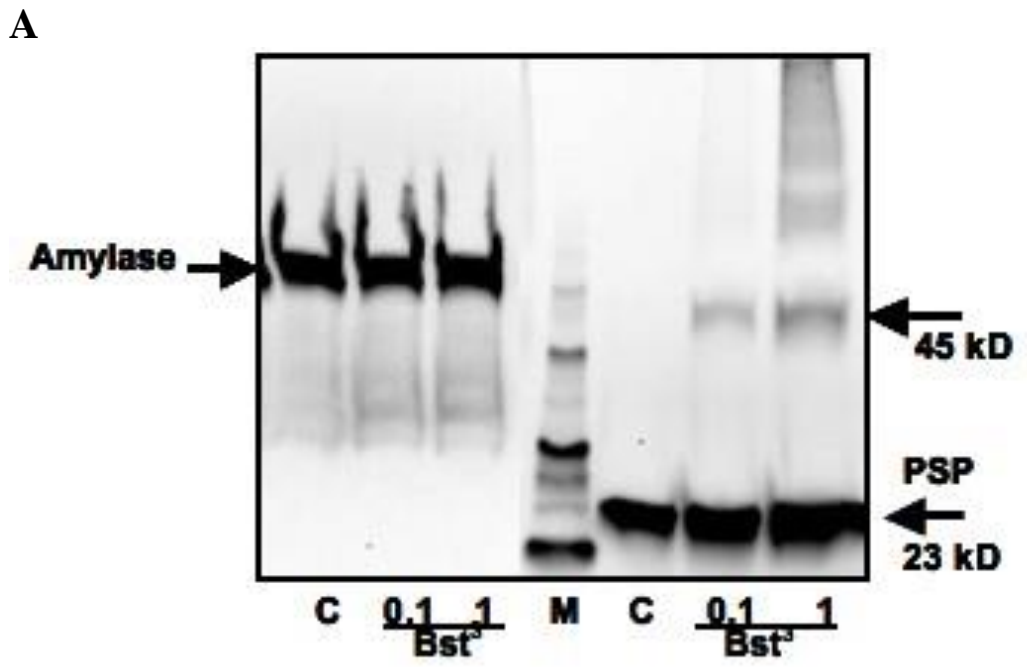

B

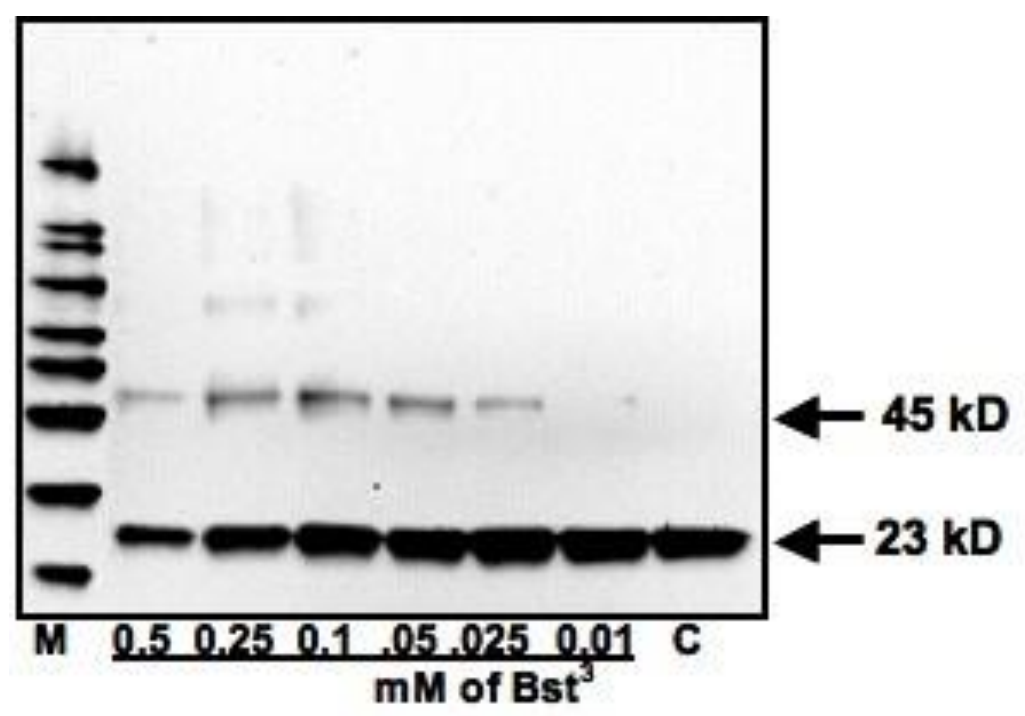

Figure 3: This experiment crosslinked native parotid granule cargo proteins using Bst ${ }^{3}$ (1.0 or $0.1 \mathrm{mM})$. SDS-PAGE and western blots with antibodies specific for either PSP or amylase were used to identify crosslinked complexes. The cargo protein amylase did not crosslink at either concentration. Native PSP is crosslinked into a $45 \mathrm{kDa}$ complex, twice the size of PSP, suggesting a dimer. The $45 \mathrm{kDa}$ complex was observed even at very low concentrations of $\mathrm{Bst}^{3} . \mathrm{C}=$ control $\mathrm{M}=$ marker 


\section{AFFINITY BINDING EXPERIMENTS}

The goal of the affinity binding is to directly test the possibility of PSP homodimerization. First the GST-PSP fusion plasmid was made and expressed in bacterial cells. The bacterial lysates were quantified and incubated with glutathione sepharose beads for one hour allowing time for the GST-PSP fusion protein to bind to the bead. In conjunction with the bacterial lysates, rPSP-V5 was translated using reticulocyte lysate kits. The V5 epitope tag was used to specifically probe the reticulocyte lysate-translated protein. These lysates were incubated on to the glutathione affinity beads and incubated for one and a half hours. The resin beads were washed extensively with $5 \mathrm{ml}$ of PBS five times. Any bound proteins were striped off the beads by heating in $\beta$-mercaptoethanol sample buffer and run on an SDS-PAGE gel. Western blot transfer with an antibody probe for the V5 epitope tag showed repeated experiments of PSP dimer formation. Controls were done by using GST alone as a control bacterial lysate. Experiments varied on whether or not background was found in the binding experiments. The control reticulocyte lysate used, chloramphenicol acetyl-transferase (CAT), which is similar in size and tag as PSP was translated and incubated onto the glutathione affinity beads and no signal was seen. 
Figure 4: Affinity binding scheme.

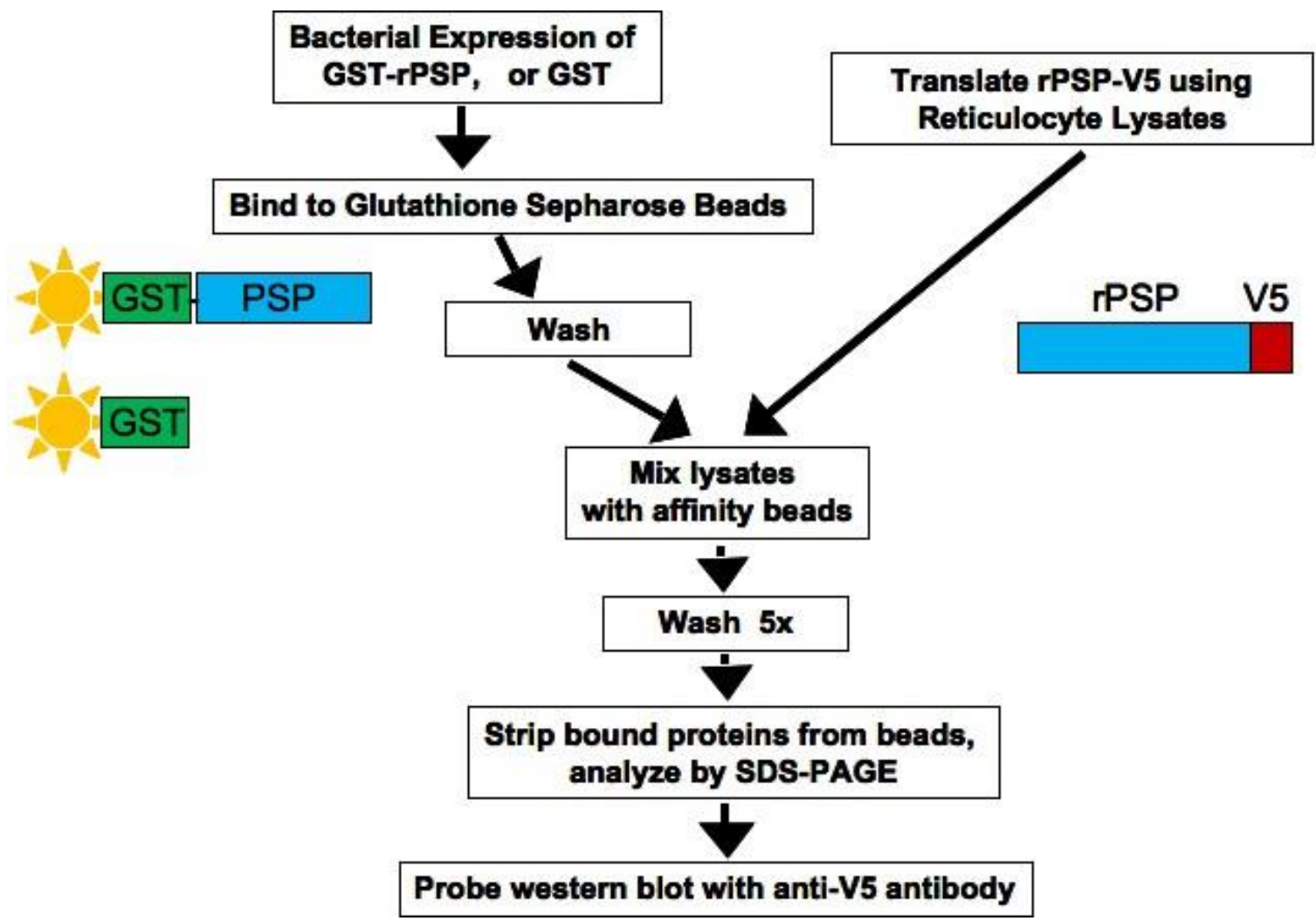

Figure 4: This diagrams the major steps of the GST-PSP affinity binding experiments.

Please see the affinity binding protocol for the complete method. 
Figure 5: Bacterial Lysate PSP Proteins.
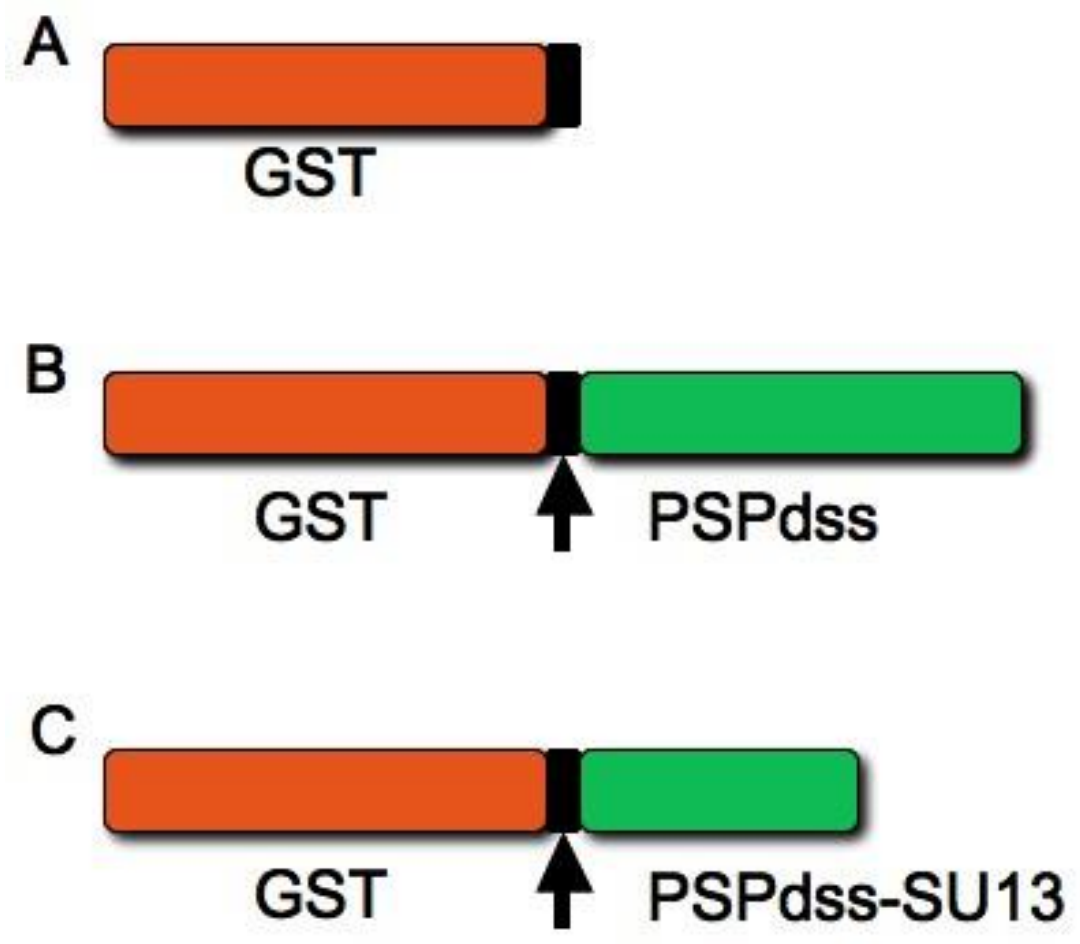

Figure 5: Shows the schematics of all GST bacterial lysate proteins that were used throughout the project in testing PSP dimerization. A, GST bacterial lysate with no PSP was used as the control resin in most of the experiments. B, GST-PSPdss bacterial lysate was used as our study lysate. C, GST-PSPdss SU13 bacterial lysates delete the necessary hydrogen bonds at the last 13 amino acids, thought to be involved in dimer formation. 
Figure 6: Reticulocyte Lysate PSP proteins.

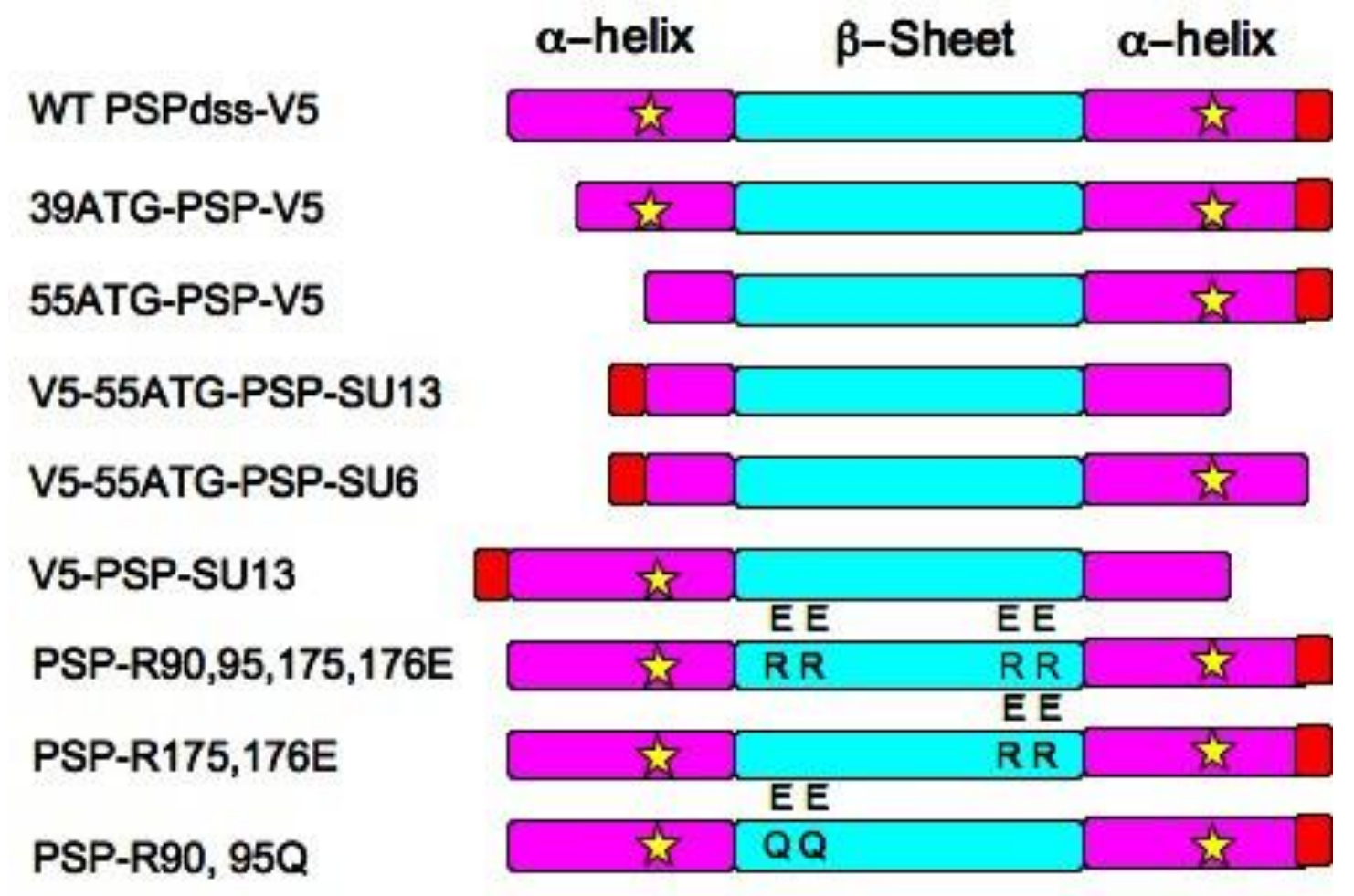

Figure 6: Illustrations of all the PSPs translated in reticulocyte lysates used in the experiments. Yellow stars represent the hydrogen bonding regions. Red rectangles represent V5 epitope tag used to probe the presence of protein on the western blot membrane. The last three clones represent the point mutations used to test the stacked model. Amino acids that had been identified to inhibit lipid binding were mutated to neutral or charged amino acids. R represents Arginine (+ charged); E represents Glutamic acid (- charged); Q represents Glutamine (uncharged) 


\section{OPTMIZING AFFINITY BINDING EXPERIMENT}

\section{Repeatability of Protocol}

Our first objective was to optimize the affinity binding experiment and test the dimerization of PSP. Equal protein amounts of GST-PSP and GST bacterial lysates were incubated with glutathione beads to allow the GST to bind. The beads were washed and then incubated with $15 \mu$ of rPSP-V5 programmed reticulocyte lysate. After incubation, beads were washed extensively. Any remaining bound proteins were stripped from the beads, run on an SDS-PAGE gel, and transferred to a nitrocellulose membrane by western blotting. The membrane was probed with anti-V5 antibody which can detect only the PSP-V5 and not the GST-PSP. The membrane was then developed with an HRPlinked secondary antibody and the Pierce SuperSignal West Pico Chemiluminescent Substrate and the image in Figure 7 was captured on a Kodak ImageStation. The experiment was carried out using cold sterile PBS as our buffer. On the Kodak image, odd lanes represent GST-PSP bacterial lysate glutathione resin with the WT PSP-V5 reticulocyte lysate bound. Lanes 2,4, and 6 contained GST (No PSP) resin with the same PSP-V5 reticulocyte lysate as our negative control. The gel load is the amount of PSP-V5 lysate added to the GST-resin to compare to the amount bound, and verify protein expression using the TNT kits. In this experiment, there was a clear signal in the GSTPSP resin lanes and a much weaker signal in the GST-resin (no PSP) lanes. Over $30 \%$ of the PSP-V5 bound to the GST-PSP resin (but little bound to the GST-resin). This experiment indicates that PSP (in PSP-V5) binds to the PSP in GST-PSP. In contrast, little to no binding was found on the GST only resin. These results indicate formation of 
a dimer or higher multimer of PSP. When we take into account the crosslinking experiments and the observed complex of $45 \mathrm{kDa}$, we infer that this is a dimer of PSP.

Figure 7: Affinity binding of GST-PSP vs GST with rPSP-V5 reticulocyte lysate.

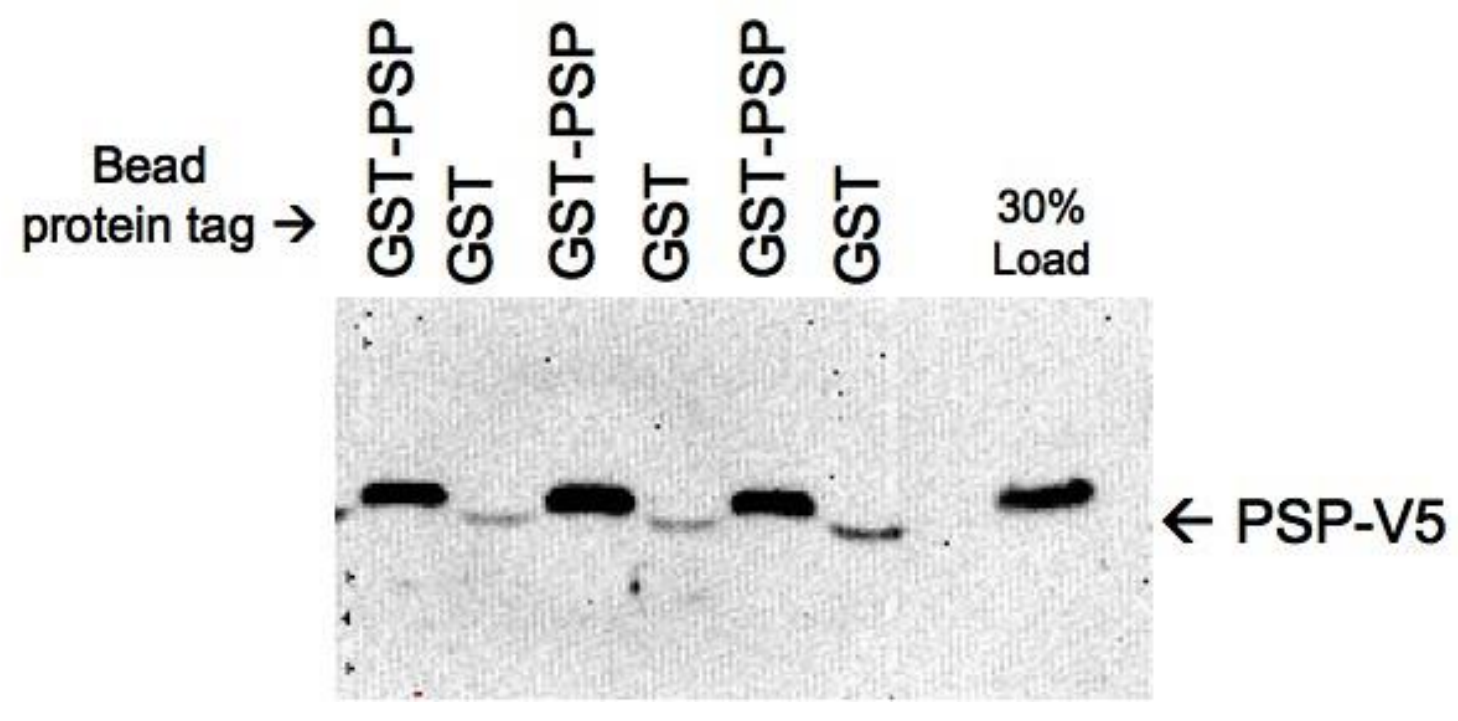

Figure 7: Image of Western showing the affinity binding experiment in triplicate to test the protocol. Lanes 1,3, and 5 resin beads had GST-PSP protein bound. Columns for lanes 2,4, and 6 had GST resin. 20 ul of rPSP-V5 reticulocyte lysate was placed in each tube and allowed to incubate. After striping bound protein from the resin we found that PSP-V5 was only present on the GST-PSP resins and little to no protein was found in the GST resin. 


\section{Affinity Binding Buffer Optimization}

Our goal for this experiment was to optimize and ensure maximal binding activity using different buffers. To maximize binding, we tested four different buffers. Buffer concentrations were referenced from other studies using coupling buffers for similar experiments. All buffers were made on the same day. The specific contents of the buffers were as follows:

Table 5: Affinity Binding Buffer Solutions

\begin{tabular}{|c|c|c|}
\hline Buffer & Contents & Results \\
\hline B1 & $\begin{array}{l}20 \mathrm{mM} \text { Tris [pH 7.4] } \\
100 \mathrm{mM} \mathrm{KCl} \\
0.1 \mathrm{mM} \text { EDTA }\end{array}$ & Good binding \\
\hline B2 & Cold, Sterile PBS & Strong binding \\
\hline B3 & $\begin{array}{l}20 \mathrm{mM} \text { Tris [pH 7.4] } \\
100 \mathrm{mM} \mathrm{KCl} \\
0.1 \mathrm{mM} \mathrm{EDTA} \\
0.05 \% \text { Igepal CA-630, } \\
10 \% \text { glycerol } \\
0.1 \mathrm{mM} \text { PMSF }\end{array}$ & Very weak binding \\
\hline B4 & $\begin{array}{l}\text { PBS, } 1 \% \text { Igepal CA-630 } \\
2 \text { mM DTT } \\
\text { Protease inhibitor tabs }\end{array}$ & No binding \\
\hline
\end{tabular}

To test the buffers, GST-PSP bacterial lysate was bound to the glutathione beads. Parallel tubes were then washed with their respective buffers (B1 - B4). Next the translated PSPV5 in reticulocyte lysate was added and incubated. Finally the affinity binding beads were washed again with their respective buffers. The proteins were then stripped from the beads and run on an SDS-PAGE gel, transferred by western blotting to nitrocellulose membrane and then probed with the anti-V5 antibody. Results in Figure 8 show good binding with buffer 1 , strong binding with buffer 2 , and little to no binding with buffer 3 and 4. It was clear that with the addition of -Igepal CA-630 in buffers 3 and 4 (previously 
termed Nonidet P40, or NP-40), a non-ionic detergent, disrupted binding between the bacterial GST-PSP and the PSP-V5. Igepal CA-630 (Octylphenoxypolyethoxyethanol) is a phenol with a chain of repeating ethoxy groups, and a separate non-polar chain therefore, it has the capacity to disrupt both hydrogen bonds, and nonpolar interactions. Even low concentrations of Igepal CA-630 prevented binding of the PSP-V5 to the GSTPSP, suggesting that PSP interaction involves hydrogen bonds, nonpolar interactions, or both. We see strong translation of the rPSP-V5 reticulocyte lysate proteins, which is seen under the columns labeled gel load. The amount of protein binding under these gel load columns were about $30 \%$ and $10 \%$ of what was put on the resin itself. This experimental result dictated the use of cold sterile PBS as our buffer of choice, as seen below in Figure 8. 
Figure 8: Affinity Binding with Various Buffers.

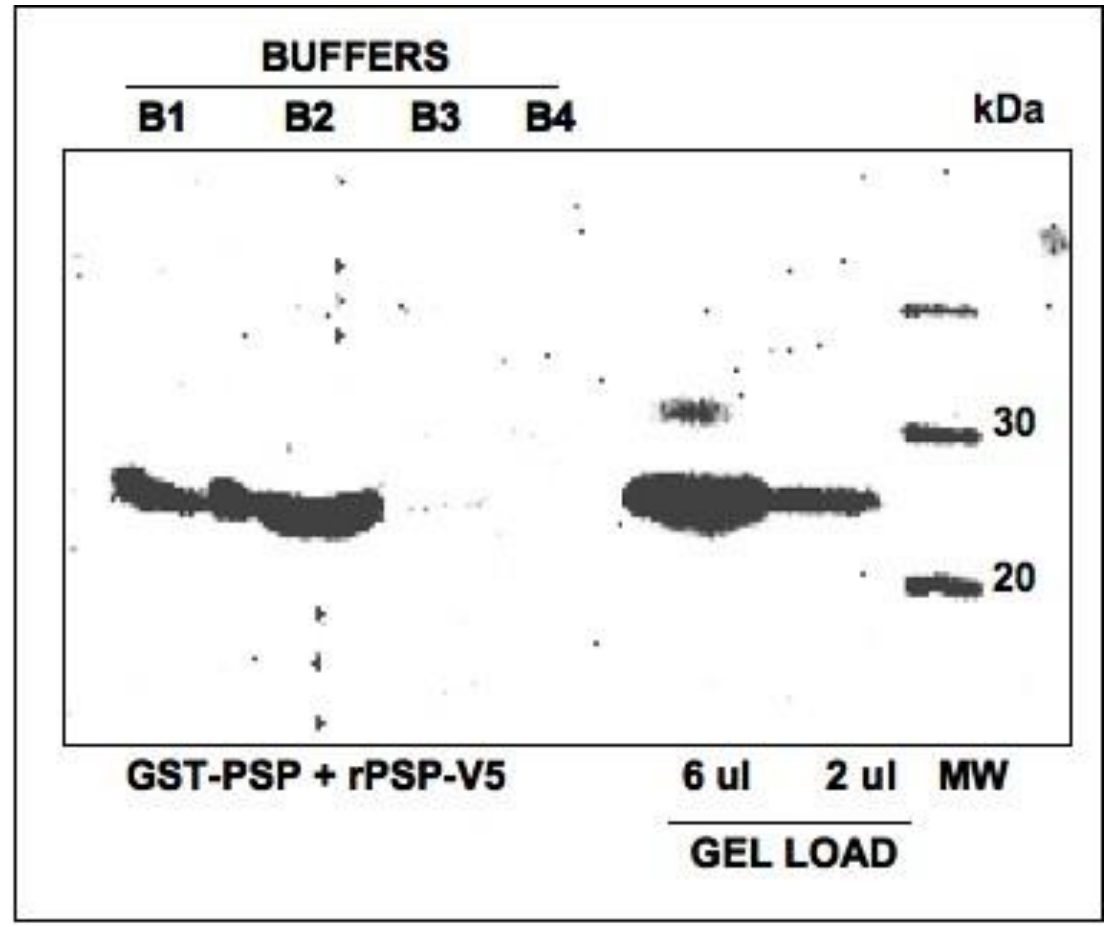

Figure 8: Binding of rPSPdss-V5 reticulocyte lysate on the GST-PSP resin was tested with 4 different buffers. Buffer compositions are listed in Table 5. Lanes 1-4 differed in buffer utilization. These lanes had the same GST-PSP bound to the resin and then rPSPV5 reticulocyte lysate bound. Buffer 1 (Lane 1) showed good binding. Buffer 2 (Lane 2) had the best binding result. Buffers 3 and 4 (Lanes $3 \& 4$ ) showed little to no binding. 'GEL LOAD' $(6 \mu 1$ or $2 \mu 1)$ is the volume of PSP-V5 lysate that was run on the gel to quantify protein expression using the TNT kits. 
CONTROL EXPERIMENT WITH CHLORAMPHENICOL ACETYLTRANSFERASE (CAT)

In the experiments above, an important negative control was the use of GST resin, which consistently showed minimal or no binding of PSP-V5. However, we wanted to test another negative control that used the same GST-PSP resin. Chloramphenicol acetyltransferase (CAT) was chosen as a control protein because it has a similar size and isoelectric point (pI) as PSP. CAT molecular weight is 323 and the isoelectric point is 5.9. PSP isoelectric point is 4.9. Both rPSP and CAT were cloned having a C-terminal V5 epitope tag and were translated in rabbit reticulocyte lysates. In this experiment, shown in Figure 9, incubation of rat PSP-V5 with GST-PSP resin showed strong binding, with minimal background binding to GST.

CAT-V5 reticulocyte lysate was incubated on the GST-PSP resin and results show no binding. Both reticulocyte lysates were also loaded directly on the gel and gave clear signals showing they were expressed and protein was made (load columns) resulting in the conclusion that CAT-V5 does not bind to the GST-PSP beads. This supports the conclusion that the binding of PSP-V5 to the GST-PSP resin is due to a specific interaction. 
Figure 9: Chloramphenicol acetyl-transferase (CAT) does not bind PSP.

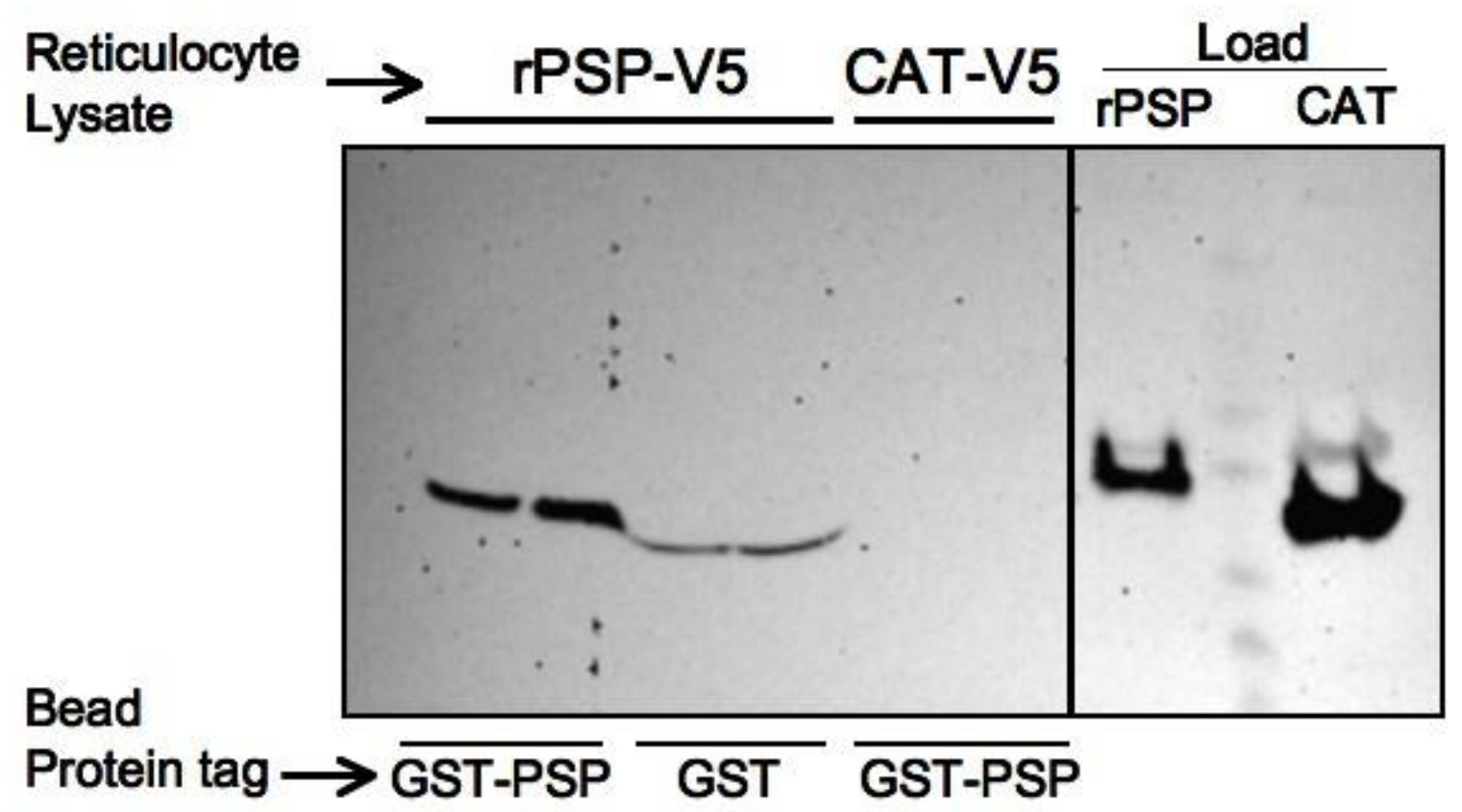

Figure 9: Results of the Chloramphenicol acetyl transferase (CAT) affinity binding experiment is show above. Lanes 1, 2, 5, and 6 have GST-PSP bacterial lysate bound to the resin. Lanes 3 and 4 have GST bound to the resin. Duplicate lanes were used with rPSP-V5 on both resins. CAT-V5 was incubated on the GST-PSP resin and results show no binding despite the fact that a substantial amount was loaded on the resin. 


\section{TESTING HUMAN PSP}

The goal of this experiment was to test human PSP binding capabilities. We hypothesized the binding of human PSP would be similar to our rat PSP dimerization results. To carry out this experiment, human PSP cDNA was cloned into the pGEX vector, sequenced and then expressed in bacteria to create lysates with GST-hPSP. We also made a human PSP cDNA with a V5 epitope tag on the end (hPSP-V5) for translation in reticulocyte lysates. Using our affinity binding approach, we bound both GST-rPSP and GST-hPSP bacterial lysates separately to glutathione beads. Beads were washed, and then incubated with the respective human or rat PSP-V5 in reticulocyte lysates. After a thorough wash the products were eluted and run on an SDS-PAGE gel. The gel was transferred to a Western membrane and then probed with the same anti-V5 antibody. Figure 10 shows the results of this experiment testing the rat model vs the human model. We see strong binding of our rat GST-PSP bacterial lysate to our rPSP-V5 protein as well as strong binding of our human GST-PSP bacterial lysate with the human hPSP-V5 reticulocyte lysate. After repeated experiments of testing both human and rat PSP proteins side by side, we were able to conclude that human PSP interacts similarly to rat PSP in the possible dimer formation. 
Figure 10: Affinity binding of Human PSP.

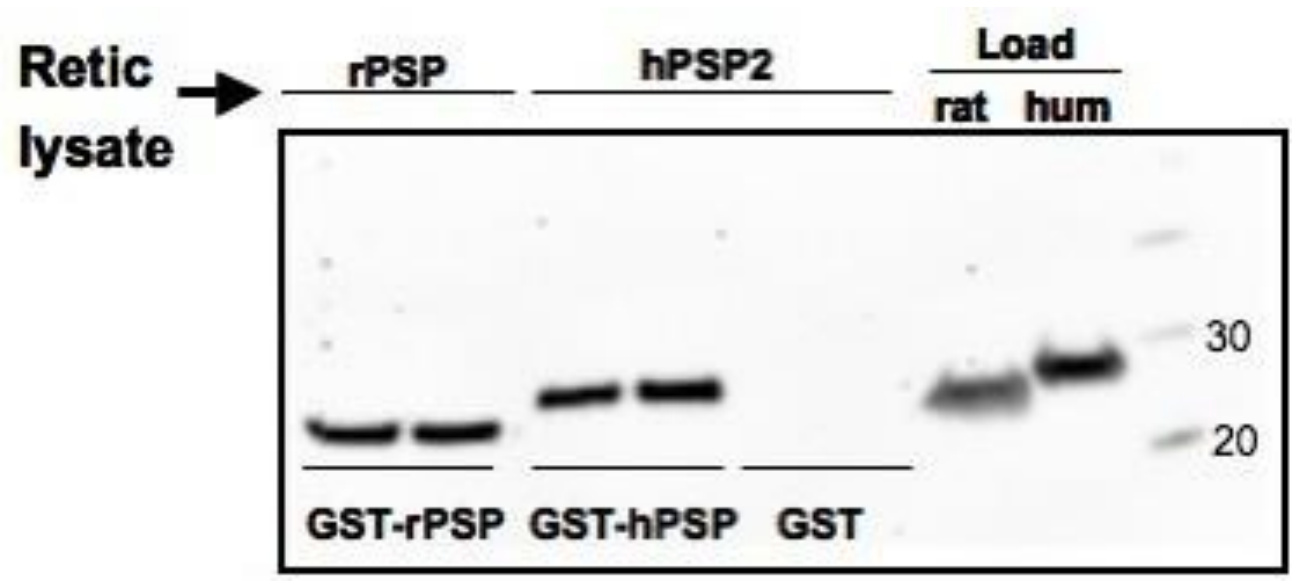

Figure 10: Two different models were tested in this affinity binding experiment. The rat model proteins were run in lanes 1 and 2. In lanes 3 and 4 we used human PSP as the other model. Results from this experiment testing the two models side by side, show GST-PSP resin beads in both rat and human bound to the PSP reticulocyte lysate, showing that even in different species our protocol and hypothesis is valid. 


\section{TITRATION OF RPSP-V5 TO GLUTATHIONE SEPHAROSE BEADS}

Once the binding buffers were optimized, it was also important to test the amount of reticulocyte lysate needed for maximal dimerization. The results of an experiment shown in Figure 11 illustrates 4 different amounts of PSP-V5 lysate added to both GST-PSP resin and control GST resin with no PSP. Results showed rPSP-V5 bound strongly to GST-PSP, with little binding to GST controls. After quantification of the intensities of the "regions of interest" (ROI) it also demonstrated that as the amount of rPSP-V5 reticulocyte lysate was increased the binding intensity increased. The negative control resins gave a much lower level of binding intensity than the GST-PSP resins. Bound PSP-V5 was found to be maximized at 20 ul of PSP-V5 reticulocyte lysates with each dimerization experiment. There were experiments that tested larger amounts of reticulocyte lysate but did not increase the "region of interest" signal. With the amount of resin used in the experiment, $20 \mathrm{ul}$ of reticulocyte lysate seemed to be the maximum amount to reach the highest binding and get the best signal. 
Figure 11: PSP Reticulocyte Lysate Optimization.

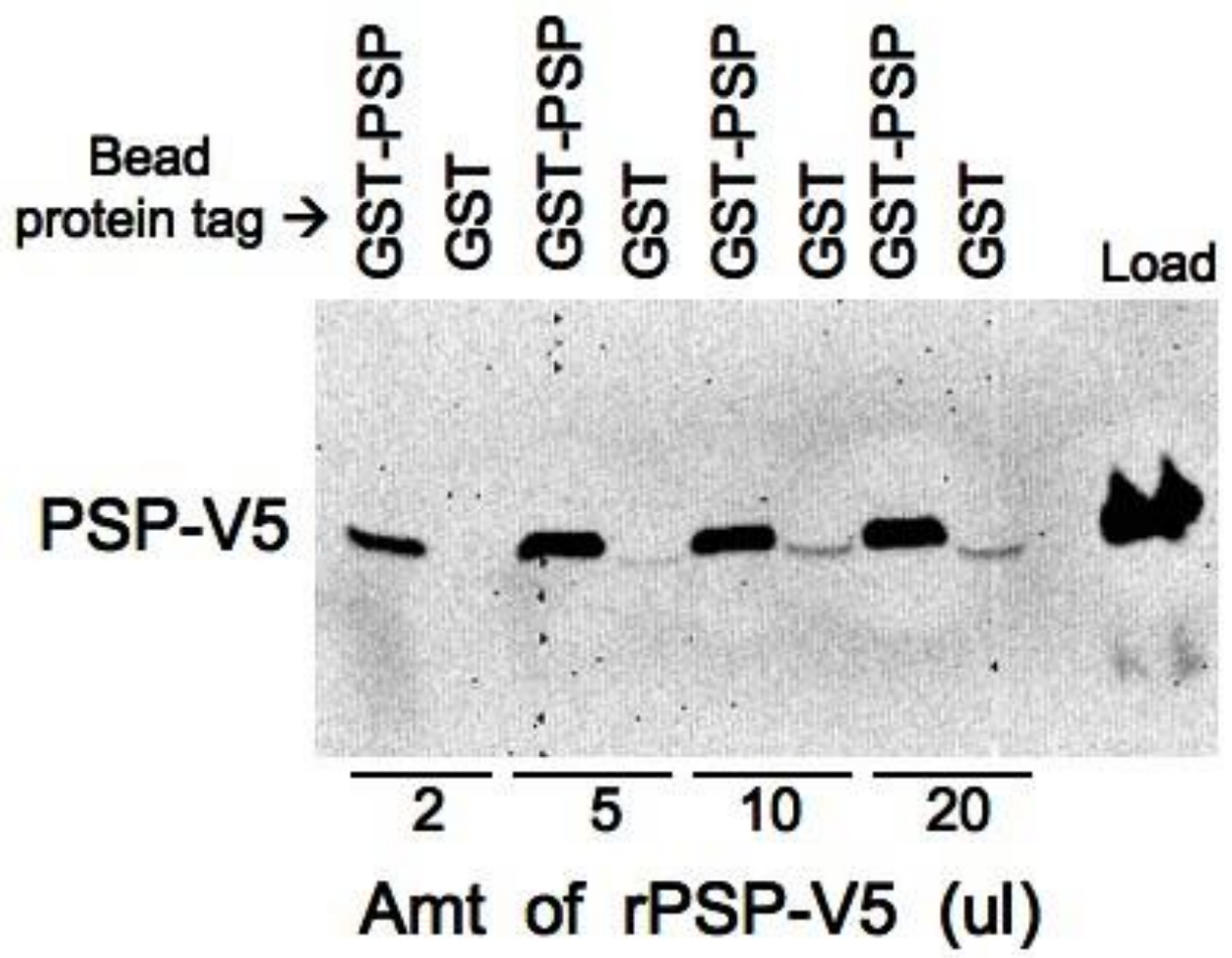

Figure 11: Lanes 1,3,5,7 had GST-PSP bound resin. Lanes 2,4,6,8 had the control GST bound resin. The amount of rPSP-V5 reticulocyte lysate added to the resin is labeled on the bottom of the image. Both experimental and control resin got the same amount of lysate on the resin and were loaded next to one another. As the amount of reticulocyte lysate increased the measured "region of interest" signal became stronger and stronger. 
Figure 12: Line Graph of GST-PSP binding vs GST Binding.

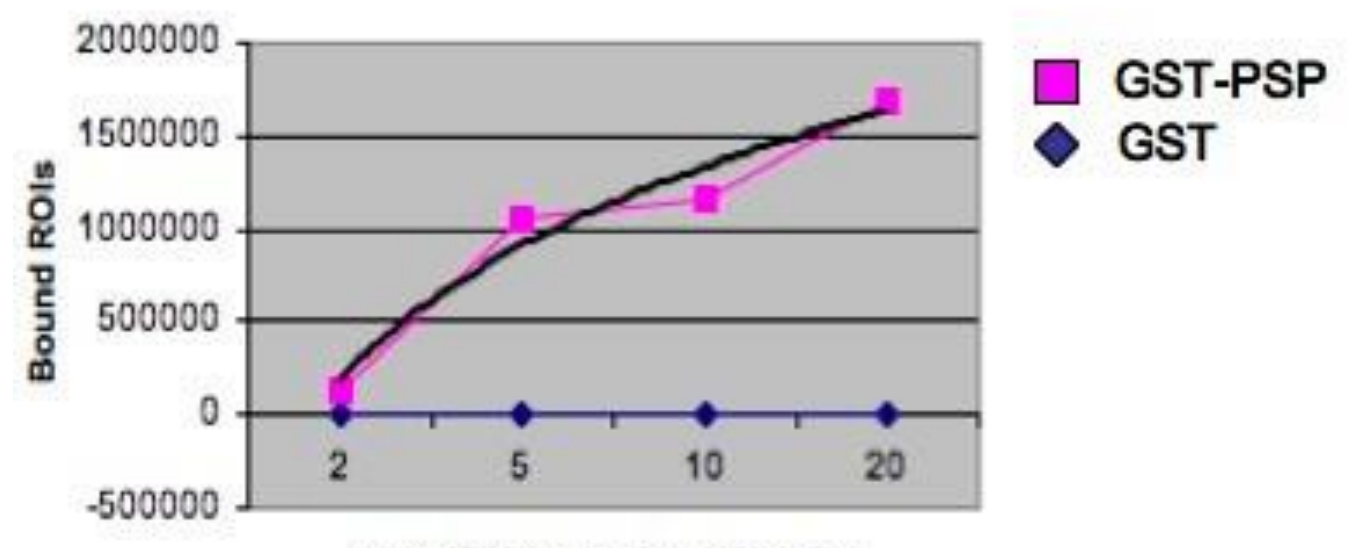

\section{Amt of Reticulocyte Added (ul)}

Figure 12: Binding of PSP-V5 in reticulocyte lysate to GST-PSP (red squares) or GST resin (blue diamonds) showed that the GST resin had little to no avidity for the GST resin and a high specificity for the GST-PSP resin as you increase the amount of reticulocyte lysate.

Along with maximizing the amount of reticulocyte lysate used in the experiments, we wanted to compare the specificity of PSP-V5 binding to either GST-PSP, or GST alone as a control. By quantifying the ROI on the Kodak Imager we see the following results after graphing the data. Figure 12 confirms strong binding of rPSP-V5 to the GSTPSP resin, and little to no binding to GST controls. As seen in the above figure, we also saw the continuing trend of increased intensity when we increased the amount of reticulocyte lysate added to the resin.

After seeing strong binding of rPSP-V5 to the GST-PSP resin, our goal was to quantify the percent of rPSP-V5 bond to the resin. The affinity binding experiment was carried out with triplicate lanes of GST alone and GST-PSP resin. $20 \mathrm{ul}$ of reticulocyte lysate were incubated with the resin and after SDS-PAGE and western blot, the membrane was probed with anti-V5 antibody. Results in Figure 16, show strong binding 
of rPSP-V5 to GST-PSP and minimal binding to the GST as a negative control.

Quantification of this experiment was done on the Kodak image machine in which the band intensities (ROI) for this experiment were measured and show binding up to $80 \%$ of added rPSP-V5. Similar results were obtained in 2 additional experiments.

Figure 13: Percent rPSP-V5 bound to GST-PSP in Affinity binding.

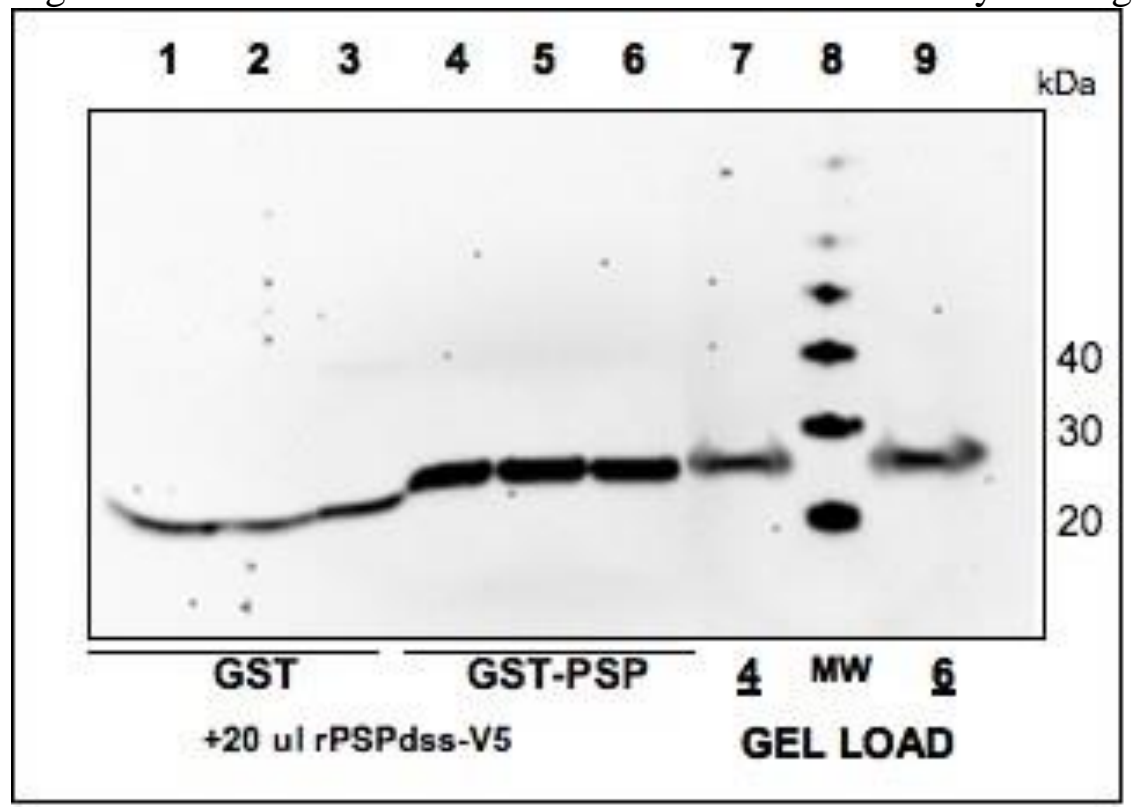

Figure 13: The percent of rPSP-V5 bound to the GST-PSP resin was examined in triplicate. Lanes 1-3 were negative controls with GST alone on the resin. Lanes 4-6 had GST-PSP immobilized on resin. Lanes 1-6 received $20 \mu 1$ of rPSP-V5 reticulocyte lysate incubated on each column. Strong binding was found with the GST-PSP resin and little binding found on the GST resin. Lanes 7 and 9 contain the rare reticulocyte lysate to verify translation. 
Figure 14: Bar Graph GST-PSP vs GST Percent Bound.

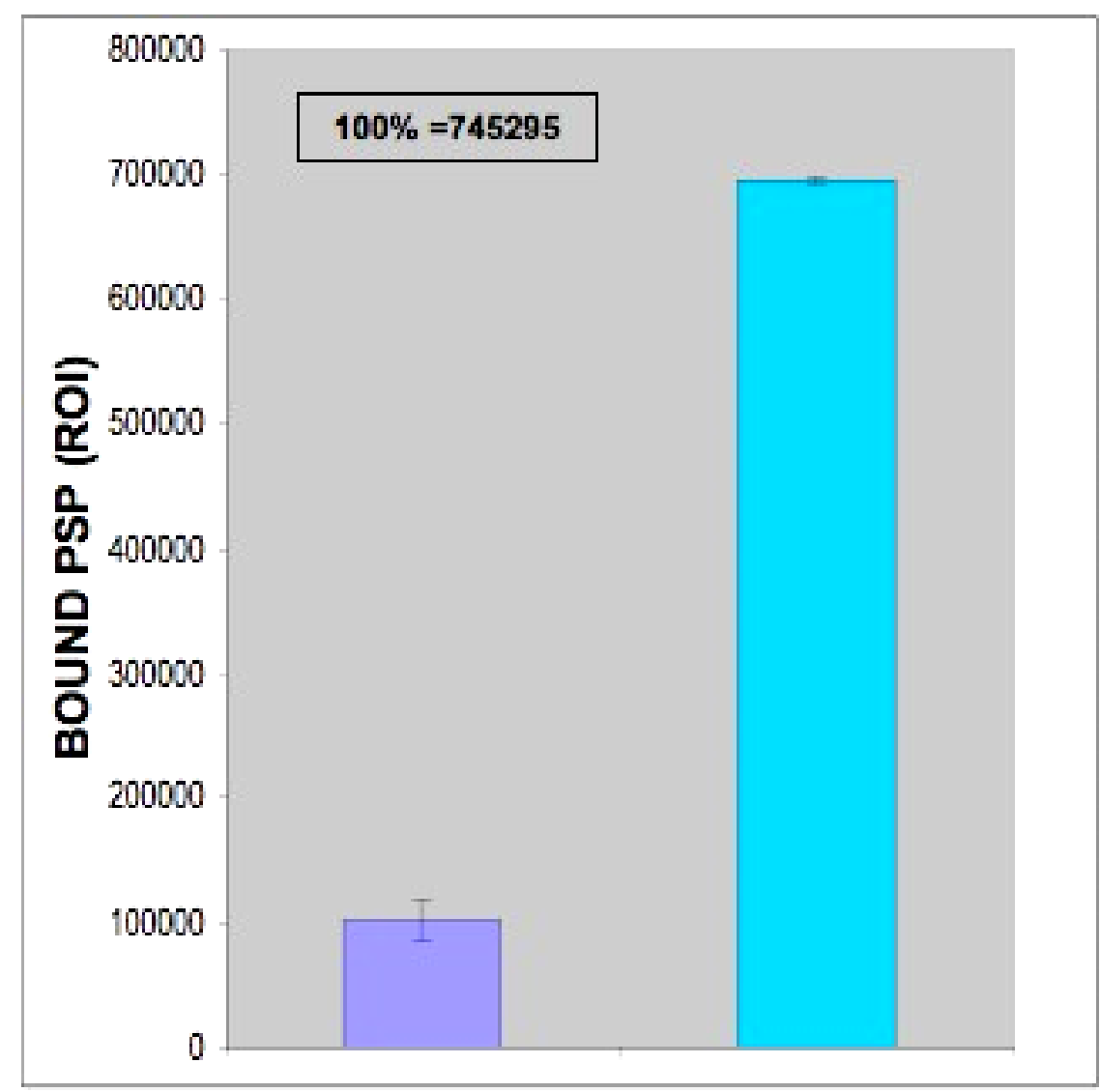

\section{GST GST-PSP}

Figure 14: In this figure it shows the amount of reticulocyte lysate bound to GST-PSP verses GST. As the bar graph shows the amount of PSP-V5 bound to the GST-PSP resin was significantly higher than the GST resin. Calculations from the ROI signal measurements show close to approximately $80 \%$ of PSP-V5 is being bound to the GSTPSP resin. 


\section{I-TASSER COMPUTER MODELING}

Using the I-Tasser program, a model was produced to represent the PSP monomer structure. Tertiary structure was based on I-Tasser for analysis of fold structure. I-Tasser iteratively threads the PSP sequence through thousands of segmental comparisons to a large number of locally related sequences, and segments are compared to the Protein Structure Data Base (PDB) to identify optimal folds, and reassembled. Figure 15 shows the predicted PSP monomer structure. Broadly, it consists of an N-terminal alpha helix region (red), a series of beta-pleated sheets (green), and a C-terminal alpha helix. The model is a hollow tube and possesses a C-terminal tab that projects out at one end. Both the $\mathrm{N}$ - and $\mathrm{C}$-terminal regions are at the same end of the tube. Figure 16 shows the small variation among the PSP monomers however with each representation there are still two alpha helixes and the beta pleated sheets. 
Figure 15: Monomer Structure of PSP.

PSP Secondary Structure:

N-terminal Helix $\quad \boldsymbol{\beta}$-sheets $\quad$ C-terminal Helix

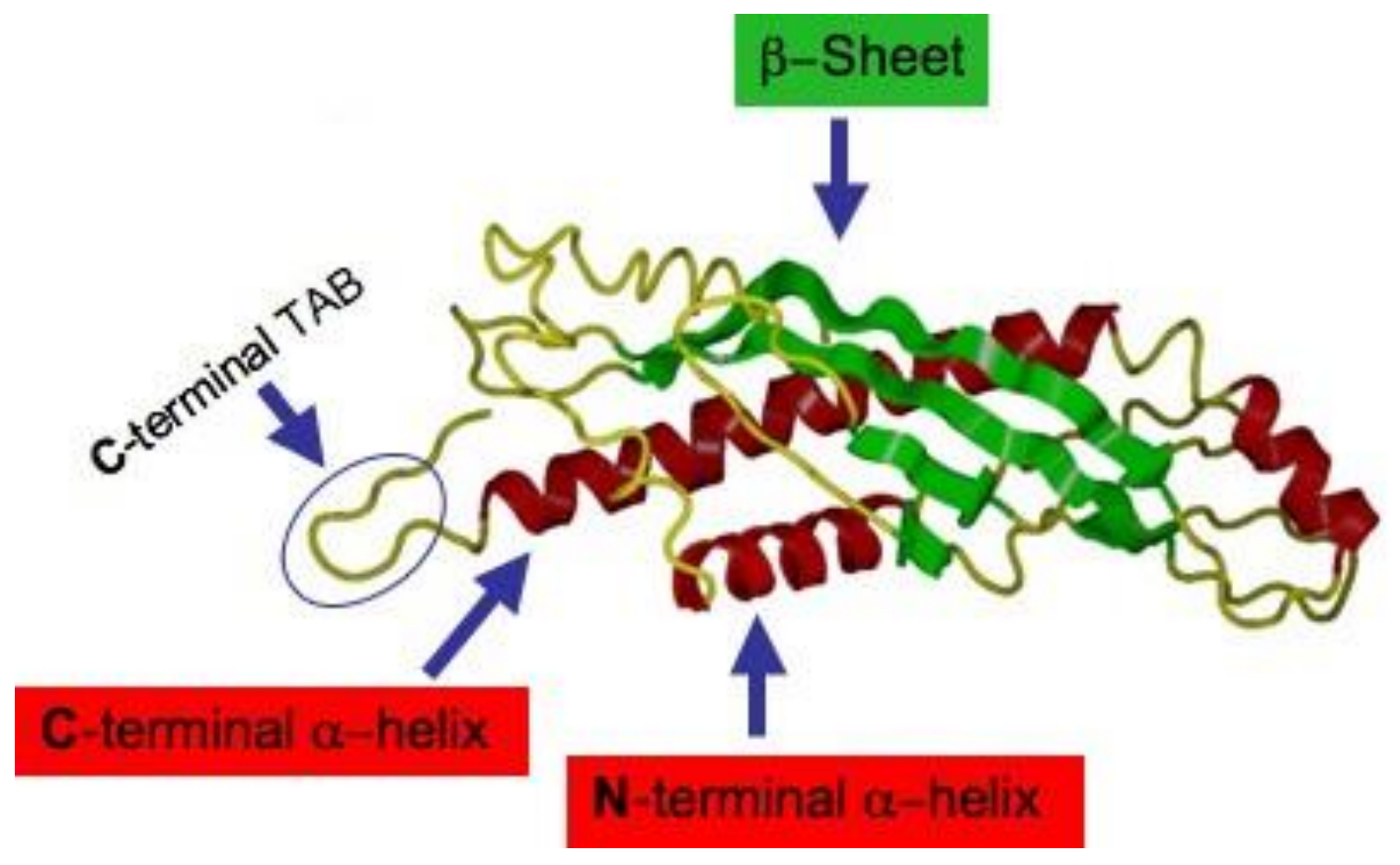

Figure 15: PSP secondary structure showing the alpha helix on the $\mathrm{N}$ and $\mathrm{C}$ terminal ends with the beta-pleated sheets in the middle. Tertiary structure is derived from I-tasser. 
Figure 16: I-tasser PSP monomer models.

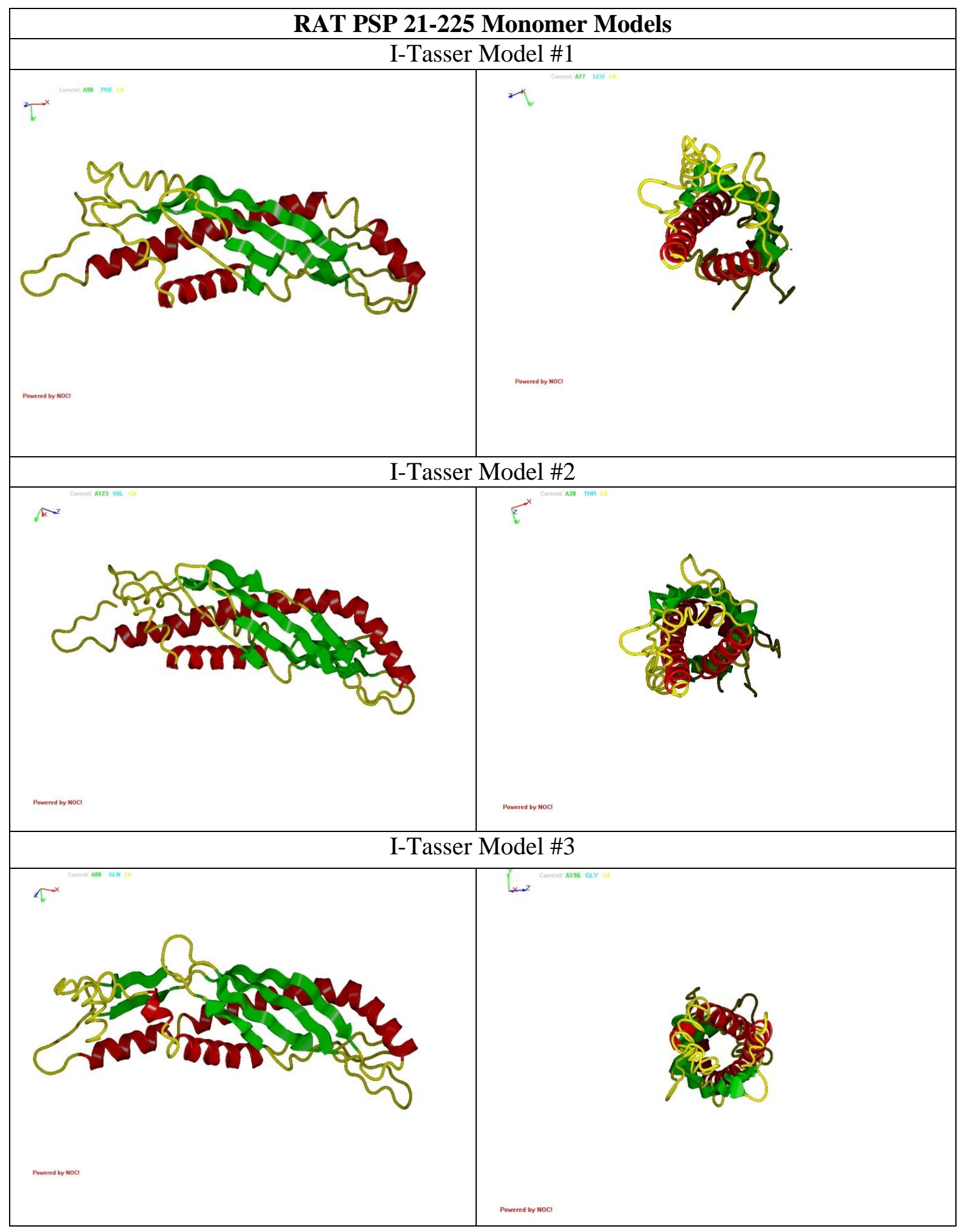


Figure 16: Different PSP monomer structures taken from I-Tasser. Each I-Tasser model is only very slightly different but still maintains the 2 alpha helixes and the beta-pleated sheet. The tertiary structure resembles a hollow tube structure, which resembles the structures of proteins in related family lineages.

\section{SYMMDOCK DIMERIZATION MODELS}

SymmDock computer analysis program was used to predict dimer formation of PSP [http://bioinfo3d.cs.tau.ac.il/SymmDock/]. SymmDock is an algorithm for prediction of complexes with $C_{n}$ symmetry by geometry-based docking [42, 43]. Results from this program show two major dimer classes with several variants of each depending on the rotation of the structure. The first dimer model of PSP was shown to form a crossed stack formation (Figure 17). This is similar to the proposed dimer of the Juvenile Hormone Binding protein (3AOE) [44], which has a similar monomer structure, but is only a distantly related protein. The second PSP dimer model is an end-to-end dimer that nearly aligns the two tubes. This is referred to as a head-to-head model (Figure 18). The ends of each tube that have the C-terminal tab interact. This dimer bears a close resemblance to the crystal structure of a monomer of BPI $[29,31]$, a related protein that is approximately twice the size of PSP. 
Figure 17: Symmdock prediction of stacked PSP dimer based on the I-tasser PSP monomer structure.

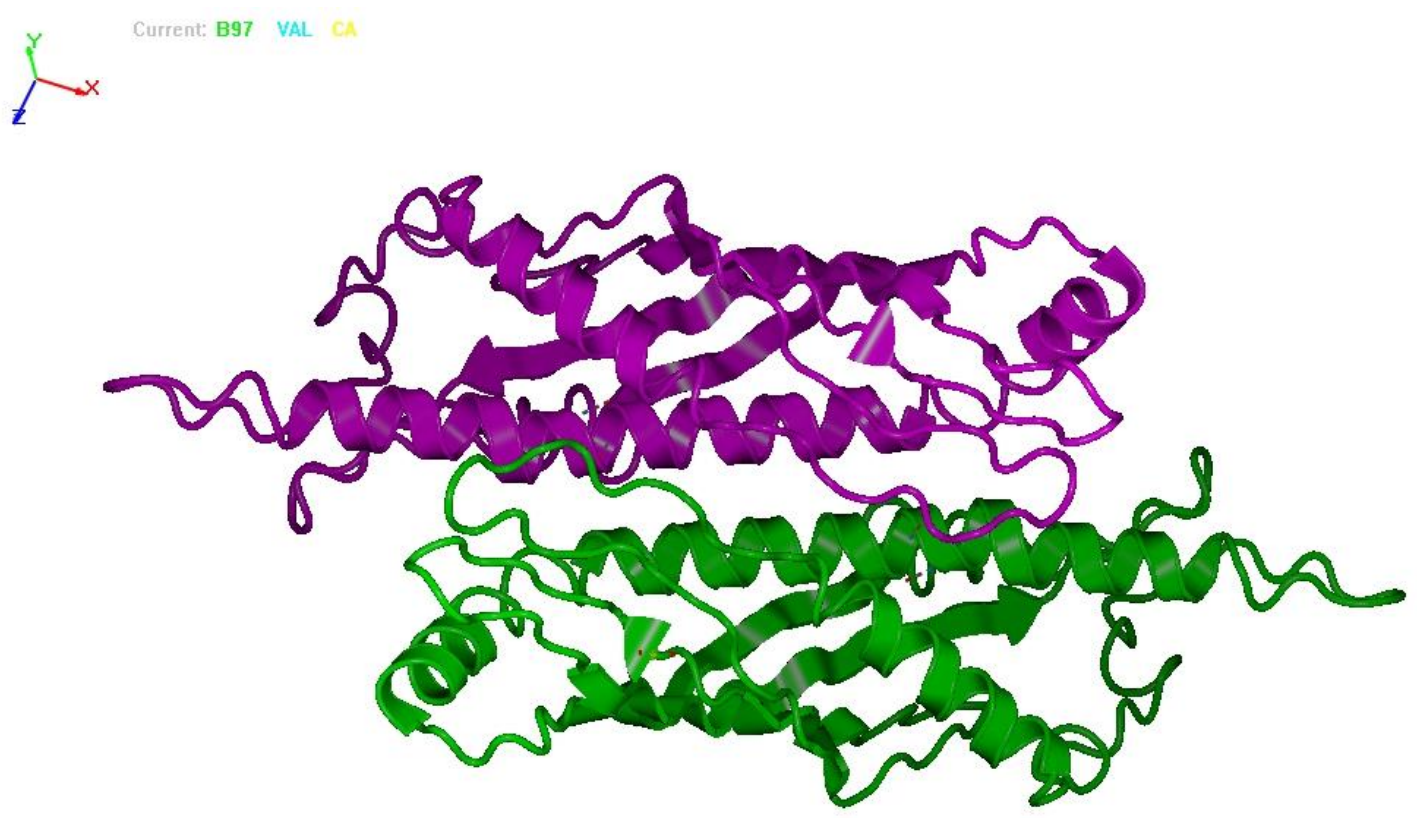

Powered by NOC!

Figure 17: The proposed stacked PSP dimer. This dimer can vary based on the rotation of the two protein monomers.

The most favorable I-tasser PSP monomer sequences were entered into SymmDock. Three head-to-head dimer models from SymmDock reported hydrogen bonding between the two monomer chains (they are highlighted in red) as well as the intrachain hydrogen bonds. 
Figure 18A: SymmDock dimer predictions based on I-Tasser model \#1.

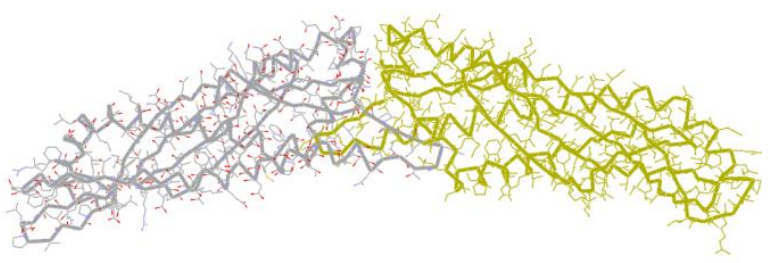

Figure 18A: The above figure is the most favored head-to-head model that was generated from the SymmDock program. This was the I-Tasser Model \#1 and SymmDock model \#3.

Figure $18 \mathrm{~A}$ is the preferred structure because 1) it has the most hydrogen bonds and therefore is likely the most stable, with a total of 13 between-chain bonds, 2) the model looks like BPI 3) structure was an output of two different computer programs (I-

Tasser \& Rosetta)

Table 6: Between chain hydrogen bonds for the head-to-head SymmDock \#3 dimer based on I-Tasser model \#1

\begin{tabular}{|l|l|l|l|l|l|l|l|}
\hline & \multicolumn{3}{|c|}{ DONOR } & \multicolumn{3}{c|}{ ACCEPTOR } & Length \\
\hline 1 & B230 & GLN & N & 52 & SER & O & 2.83 \\
\hline 2 & B229 & GLY & N & 55 & GLN & OE1 & 2.86 \\
\hline 3 & B230 & GLN & NE2 & 58 & THR & O & 3.00 \\
\hline 4 & B229 & GLY & N & 58 & THR & OG1 & 2.79 \\
\hline 5 & B229 & GLY & N & 58 & THR & OG1 & 2.79 \\
\hline 6 & B55 & GLN & NE2 & 227 & LEU & O & 3.07 \\
\hline 7 & 230 & GLN & N & B52 & SER & O & 2.77 \\
\hline 8 & 229 & GLY & N & B55 & GLN & OE1 & 2.79 \\
\hline 9 & 230 & GLN & NE2 & B58 & THR & O & 2.95 \\
\hline 10 & 229 & GLY & N & B58 & THR & OG1 & 2.82 \\
\hline 11 & 229 & GLN & N & B58 & THR & OG1 & 2.82 \\
\hline 12 & 47 & ASN & ND2 & B151 & THR & O & 3.19 \\
\hline 13 & 55 & GLN & NE2 & B227 & LEU & O & 3.07 \\
\hline
\end{tabular}

Table 6, shows hydrogen bonds that are assigned by NOC program and illustrates all of the hydrogen bonds between chains of two PSP monomers. There are a total of 329 
hydrogen bonds in the molecule. This head-to-head structure is strongly favored because it has the most inter-monomer reactions. The minimum bond length is 2.4 angstrom, the maximum length is 3.2 angstrom. The lengths of the bonds are all within normal limits. The two PSP monomers are labeled A and B. In the table when referring to monomer A there is no alphabetical label, however monomer B shows a B in front of the site in which the bond is occurring. Importantly, note that all the interchain hydrogen bonds are between the C-terminal tab and then $\mathrm{N}$-terminal helix.

Figure 18B: SymmDock dimer prediction based on I-Tasser model \#2.

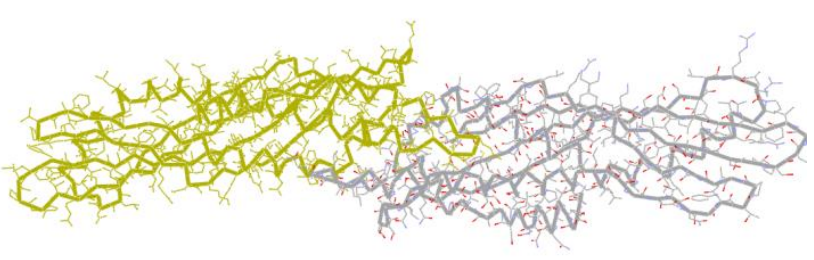

Figure 18B: The above figure is the twisted head-to-head model generated from I-tasser model \#2 and SymmDock model \#4. This figure only has eight hydrogen bonds between chains.

Table 7: Between chain hydrogen bonds for the Head-to-head SymmDock \#4 dimer based on I-Tasser model \#2

\begin{tabular}{|l|l|l|l|l|l|l|l|}
\hline & \multicolumn{3}{|c|}{ DONOR } & \multicolumn{3}{c|}{ ACCEPTOR } & Length \\
\hline 1 & B230 & GLN & NE2 & 65 & SER & OG & 3.00 \\
\hline 2 & B230 & GLN & NE2 & 65 & SER & OG & 3.00 \\
\hline 3 & B225 & ASN & ND2 & 221 & GLY & O & 3.02 \\
\hline 4 & B225 & ASN & ND2 & 225 & ASN & OD1 & 2.89 \\
\hline 5 & 230 & GLN & NE2 & B65 & SER & OG & 2.78 \\
\hline 6 & 230 & GLN & NE2 & B65 & SER & OG & 2.78 \\
\hline 7 & 225 & ASN & ND2 & B221 & GLY & O & 2.83 \\
\hline 8 & 225 & ASN & ND2 & B225 & ASN & OD1 & 3.03 \\
\hline
\end{tabular}


Of these predictions of head-to-head PSP dimer models only the first (Fig 18A) has a strong resemblance to the related protein BPI structure which has already been crystallized and studied [45].

Further enhancing our understanding of possible quaternary structures for the PSP dimer, the primary amino acid sequence was entered into the Rosetta Docking molecular modeling software. Rosetta is a library based object-oriented software suite, which provides a robust system for predicting and designing protein structures, protein folding mechanisms, and protein-protein interactions. The library contains the various tools that Rosetta uses, such as Atom, ResidueType, Residue, Conformation, Pose, ScoreFunction, and ScoreType. These components provide the data and services Rosetta uses to carry out its computations. The difference in this docking system is that it does not assume symmetry. The results from this software system showed the exact same head-to-head model which we obtained using the SymmDock software. These results added strength to that fact that the head-to-head model is the one of interest and the one we need to explore [46]. 
Figure 19: Rosetta Software 3-D Modeling.

(a)

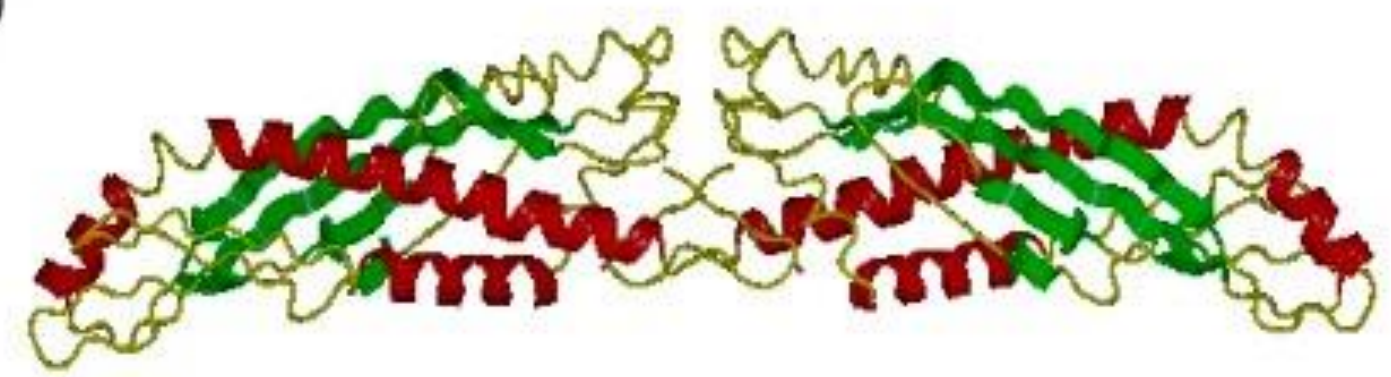

Figure 19: shows the Rosetta docking system (a) head-to-head model of the PSP dimer.

This strengthens our dimer hypothesis and narrows down the orientation in which the dimer is likely to form. 
Interestingly, Kolodziejczyk et al. have published a paper that compares the structure of Juvenile Hormone Binding Protein (JHBP) and its similarities to Human Lipid- Binding Protein. JHBP is a hormone carrier that has a large affect on insect development. It was shown that in the context of crystal packing, JHBP shows intermolecular B-sheet interactions that result in a dimer [47] that resembles that stacked version of our PSP dimer. Due to the close relationship of this molecule to the BPI family of which PSP is also a part, it makes sense for us to explore the stacked PSP dimer model as well. 
Figure 20: Juvenile Hormone Binding-Protein (JHBP) dimer.

(a)

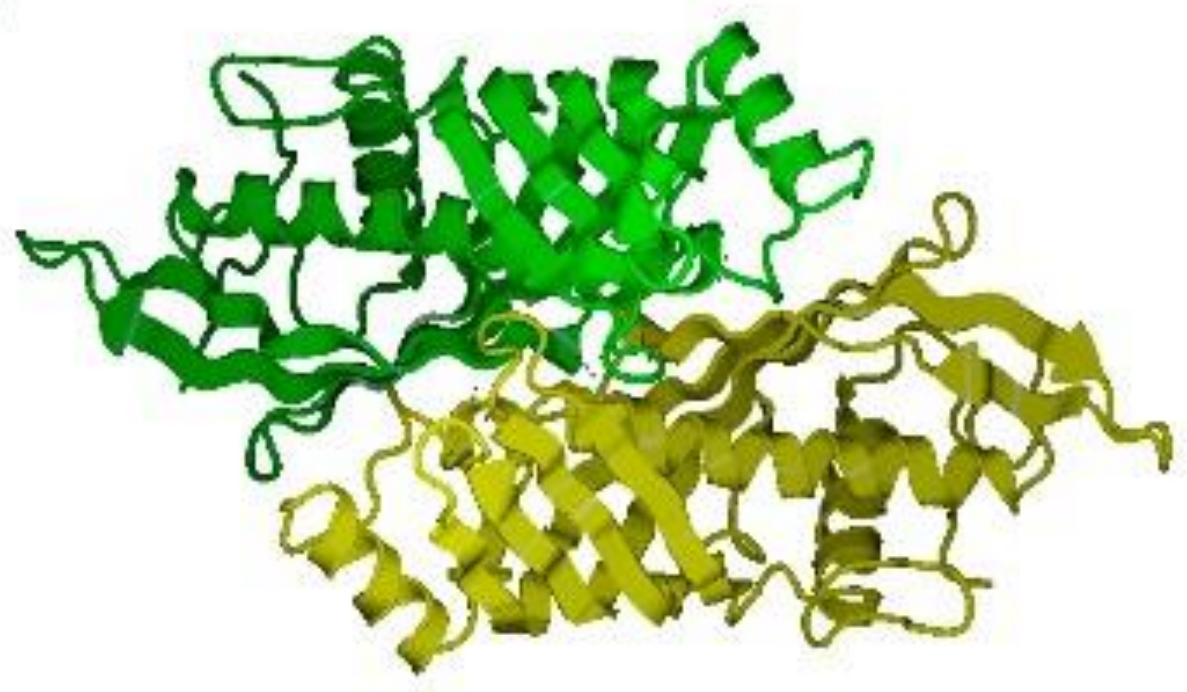

(b)

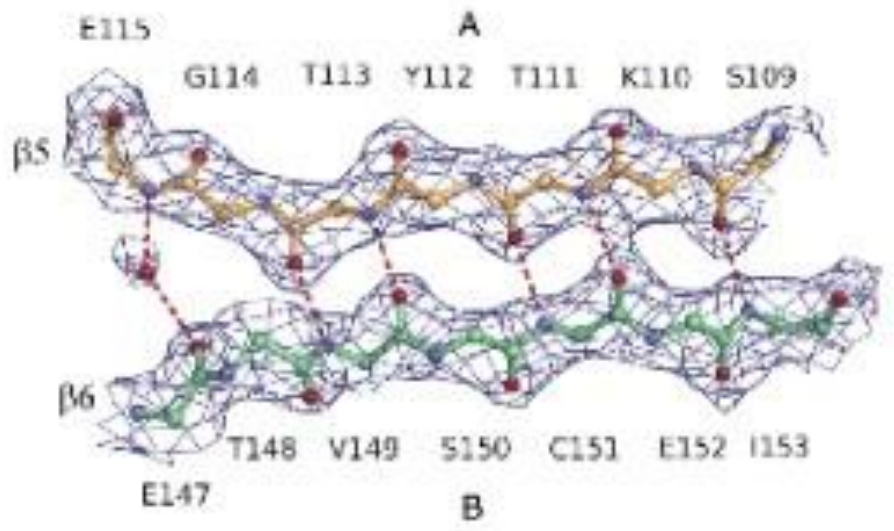

Figure 20 shows two hydrophobic cavities within the core of JHBP and their accessibility in the context of crystal packing. a) shows the ribbon structure resembling the stacked model of PSP. b) shows two monomers of JHBP in which interactions of B-sheets are being shown forming a dimer. 
It is due to the resemblance and common nature of PSP to the BPI family proteins as well as two different computer modeling programs in which we observed that PSP may form a dimer two possible ways. One way being the head-to-head model that resembles the BPI super-family protein. The other being the stacked model, which both computer modeling systems show is a possibility. It was due to these findings that we set out to test these two models.

Figure 21: Computer analysis of the representative models of the PSP dimer.

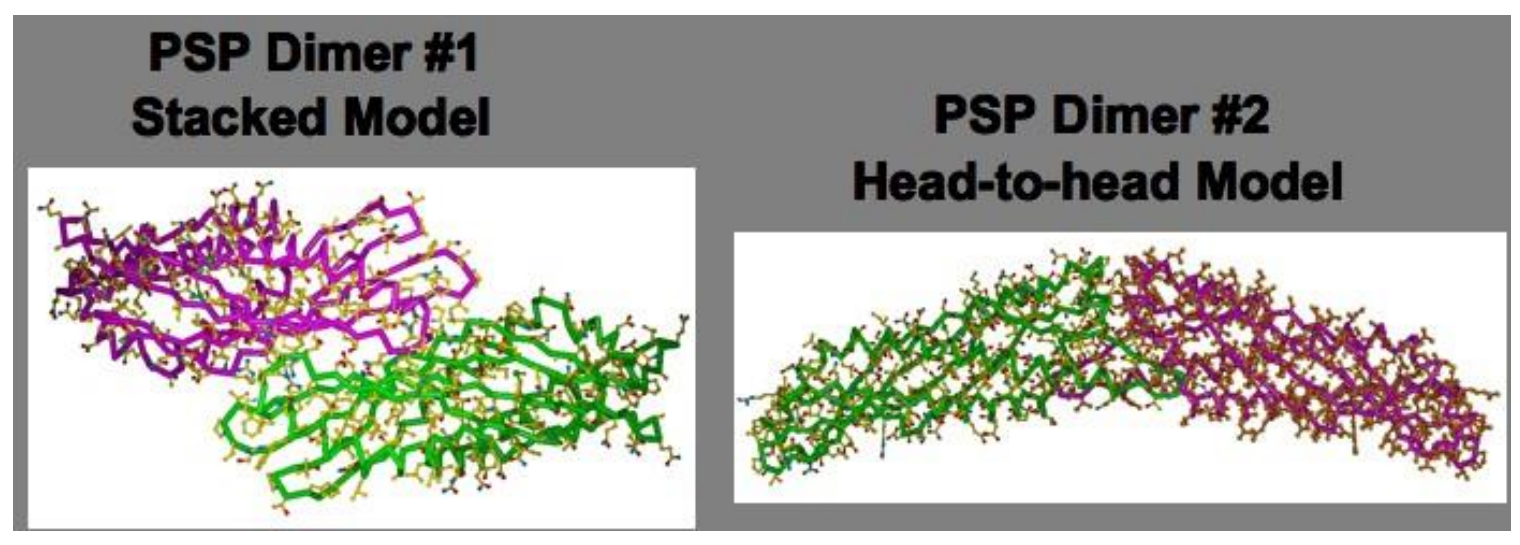

Figure 21: I-Tasser computer analysis shows the stacked PSP dimer model shown to the left. On the right the head-to-head dimer model shows the C-terminal tabs interacting to form a dimer. 


\section{TESTING PSP STACKED DIMER MODEL WITH PSP MUTANTS}

A set of mutants was made to test the stacked PSP dimer model that was predicted by SymmDock. Quaternary structure of a dimer is typically stabilized by hydrogen bonding between polar R-groups, ionic bonds between charged R-groups, hydrophobic interactions between nonpolar R-groups, and disulfide bonds. The surface of the PSP protein has local regions of polar, charged, or non-polar amino acid R-groups which may help stabilize a stacked dimer. We tested the effect of mutation of four basic amino acid residues at the surface of PSP on the ability of PSP to form homodimers. Mutation of the basic residues could disrupt ionic bonds that stabilize the dimer, and mutation of the charges would likely disrupt the charge distribution across the surface of PSP. Either of which could prevent dimer formation by PSP. 
Figure 22: PSP Protein Mutan39ts and Truncations.

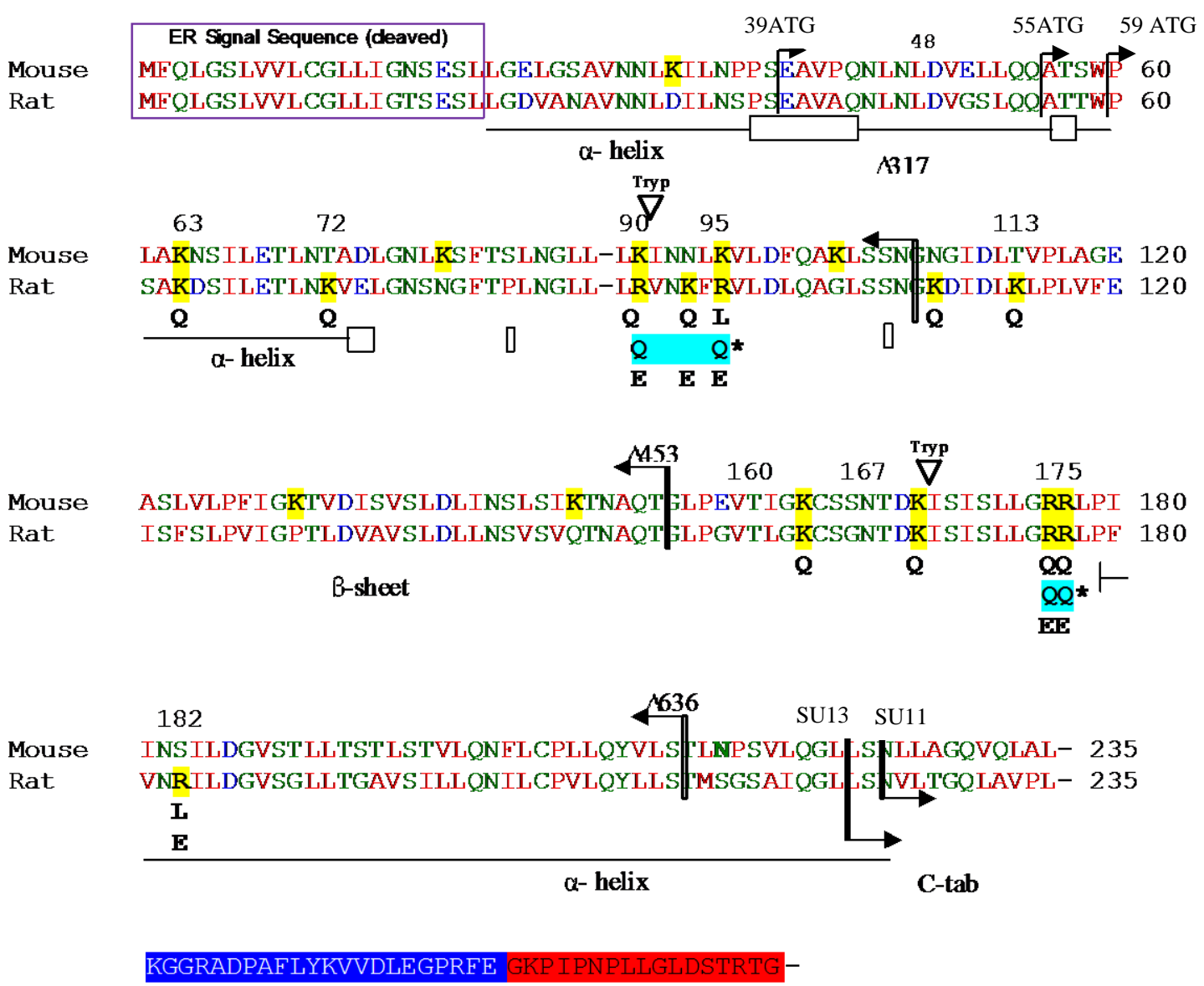

Figure 22: The sequences of rat and mouse PSP are aligned. In order to define which dimer model PSP resembles, point mutations of basic amino acids were introduced into rat PSP, as shown in blue bold beneath the wild type sequence. Theses point mutations were found to be important for binding to lipids. In addition, $\mathrm{N}$-terminal or C-terminal deletions (shown by bent arrows) were made for studying the dimerization of the end-toend dimer model. The dark blue is the attB part of Gateway cloning. The red is the V5 tag. The lighter blue with astricks $(*)$ represents a double mutant. 
Figure 23: Clones for rPSPdss mutants to test the stacked dimer model.

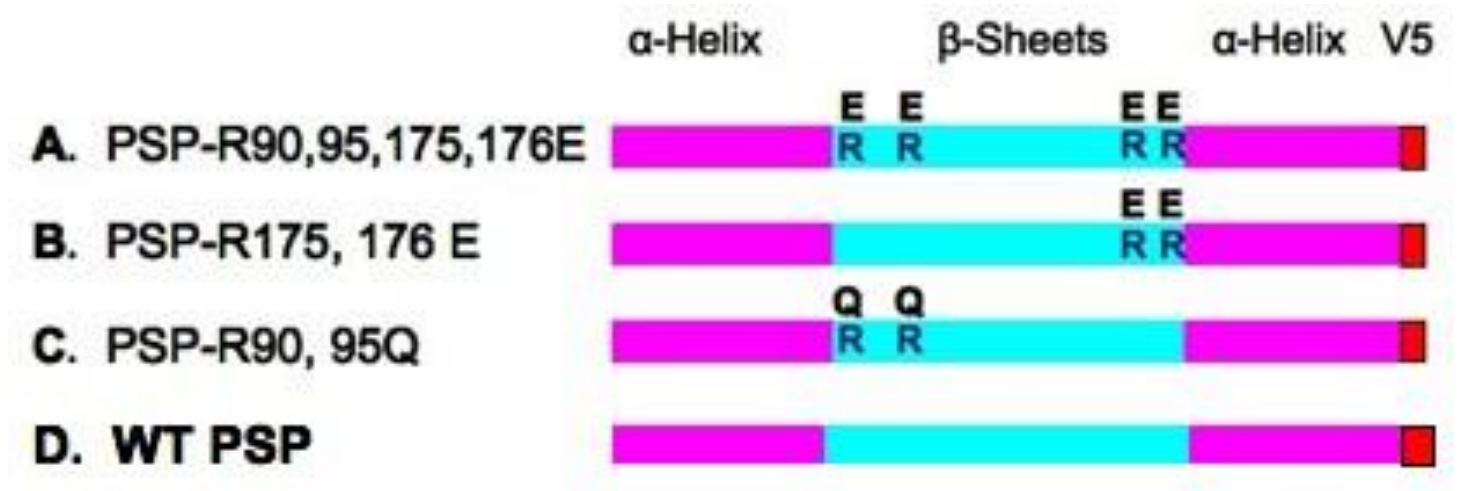

Figure 23: shows a representation of PSP as a monomer having alpha-helixes at the beginning and end of the PSP sequence flanking beta pleated sheets. Each of the clones has a V5 tag, allowing us to identify whether or not the protein was binding. Mutants A, $\mathrm{B}$, and $\mathrm{C}$ possess amino acid changes displayed by the capital letters. In PSP mutants A and $\mathrm{B}$, the $\mathrm{R}$ amino acids were switched out to E's. In PSP mutant $\mathrm{C}$ the R's were changed into Q.

The mutants shown in Figure 23 are important in that they are known to disrupt or inhibit lipid binding which could also possibly disrupt dimerization in the stacked model. To test these mutants, an affinity binding experiment was carried out initially with both GST-PSP and GST bacterial lysates incubated on to the glutathione resin. Resins were incubated with $20 \mu \mathrm{l}$ of a particular rPSPdss mutant which was allowed to bind to the protein on the resin. Experimental results show that none of the mutations inhibited binding of rPSPdss-V5 lysate on the GST-PSP resin. In each case there was little or no binding to the GST resin (these results are shown on Figure 24) 
Figure 24: Affinity binding with PSP mutants testing stacked PSP dimer model.

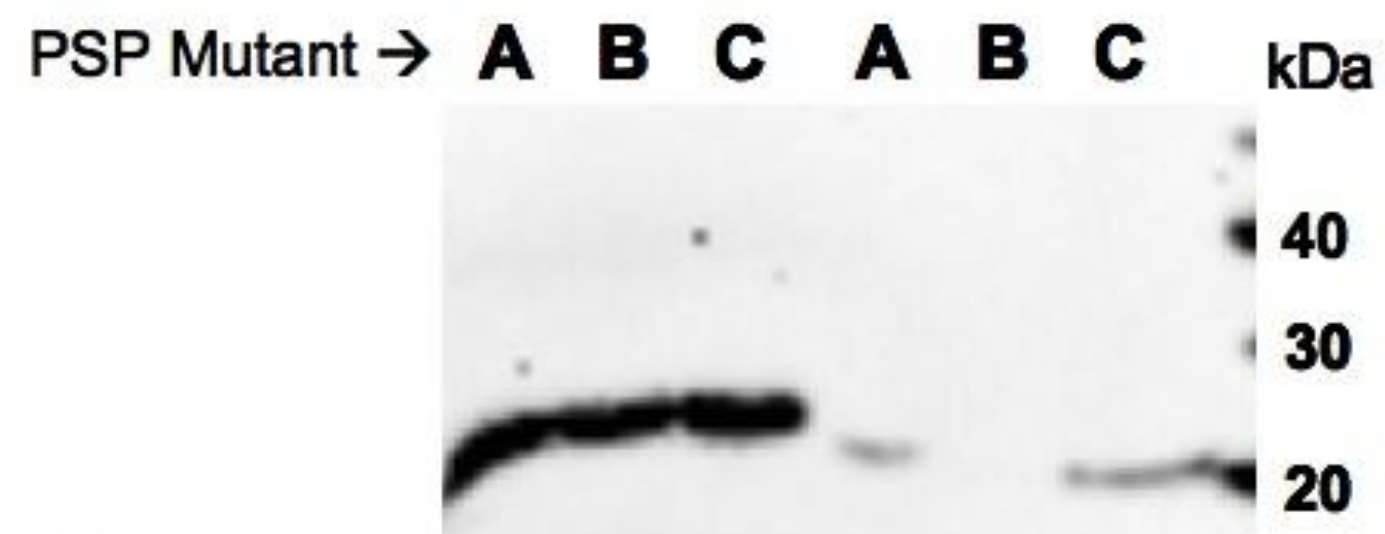

\section{Bead protein tag $\rightarrow \overline{\text { GST-PSP }}$ GST}

Figure 24: Mutants are labeled at the top of the figure. In the first three lanes GST-PSP bacterial lysate was on the resin bead in the last three lands GST was the protein on the resin bead. The mutants incubated with the GST-PSP protein were present after it was striped from the resin bead. Mutants incubated with the GST protein showed little to no binding. The results of this experiment showed that the charged amino acids that contribute to lipid binding studies do no inhibit or participate in dimer formation. 


\section{TESTING PSP HEAD-TO-HEAD DIMER MODEL WITH PSP MUTANTS}

The second PSP Dimer model interacts via the C-terminal (or carboxy-terminal) tab crossing the line of symmetry and interacts with the opposite chain N-terminal alpha helix. This is the more intriguing model of the dimer due to its striking resemblance to the crystal structure of the BPI superfamily. PSP is distinctly related to this bigger protein superfamily. Figure 25 shows the predicted hydrogen bonds thought to be essential for dimerization. It is from this model that we use varying clones to test this head-to-head dimer model by knocking out the 5 hydrogen bonds that are thought to participate in the dimer formation.

Figure 25: Hydrogen bond modeling in the PSP head-to-head dimer.

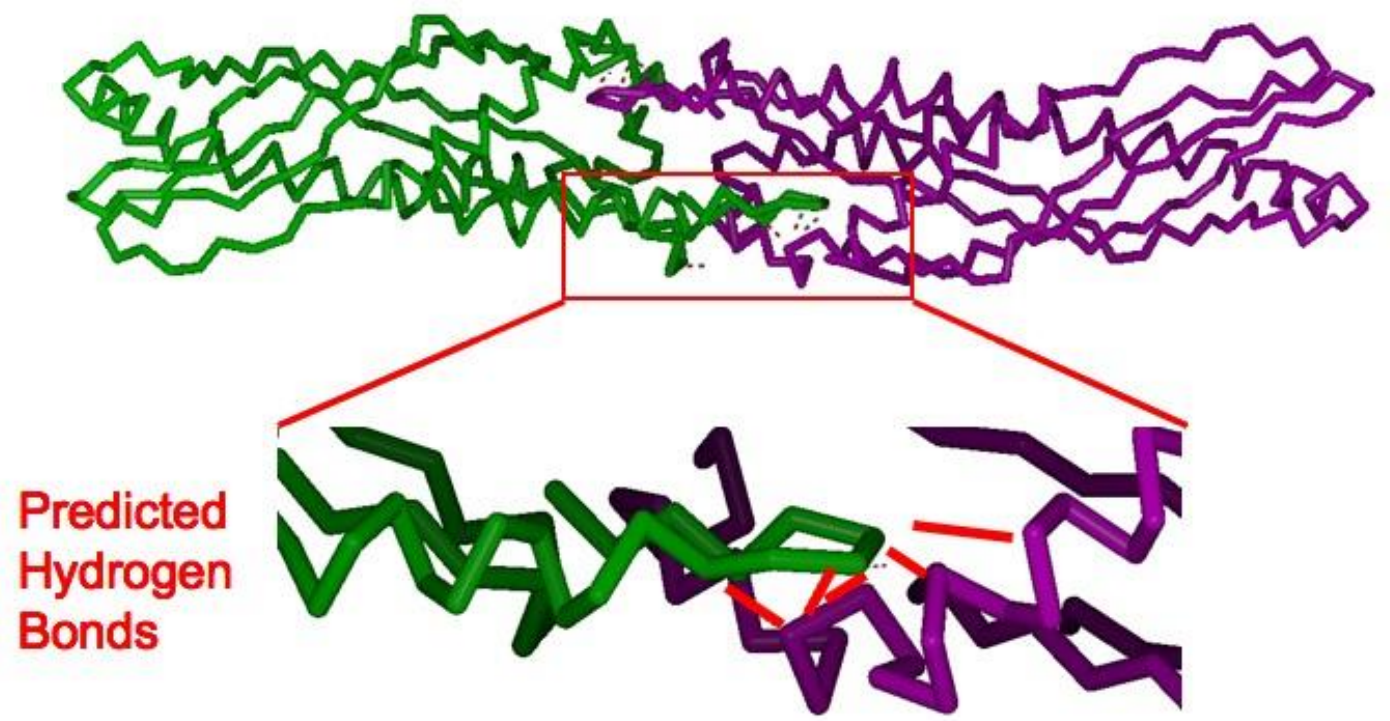

Figure 25, the PSP head-to-head dimer model has been rotated on its side to illustrate the predicted hydrogen bonds between the C-terminal tab of one PSP monomer with the Nterminal alpha helix of the other monomer. 
In order to study the head-to-head dimer models, several clones were made (Table 2) and used to test this model. These models showed 5 hydrogen bonds that could possibly participate in the head-to-head dimer formation near by connecting the $\mathrm{N}$ and $\mathrm{C}$ terminals (Figure 25). To test this model, clones that possessed one, two or no hydrogen bonding regions were used. We found in our series of experiments that if areas for hydrogen bonding (whether there was one or two hydrogen bond sites) were present in the PSP sequence, binding would be seen with the GST-PSP resin, resembling a dimer. However if no sites for hydrogen bonding are left in the reticulocyte lysate mutant PSP sequence, represented by the V5-55ATG-PSP- $\Delta 13$, results show no binding to the GSTPSP resin protein. From these experiments we can determine that deletion of the interchain hydrogen bonds between the $\mathrm{N}$ - and $\mathrm{C}$-terminal residues prevents dimerization. 
Figure 26: Testing the head-to-head PSP dimer model.

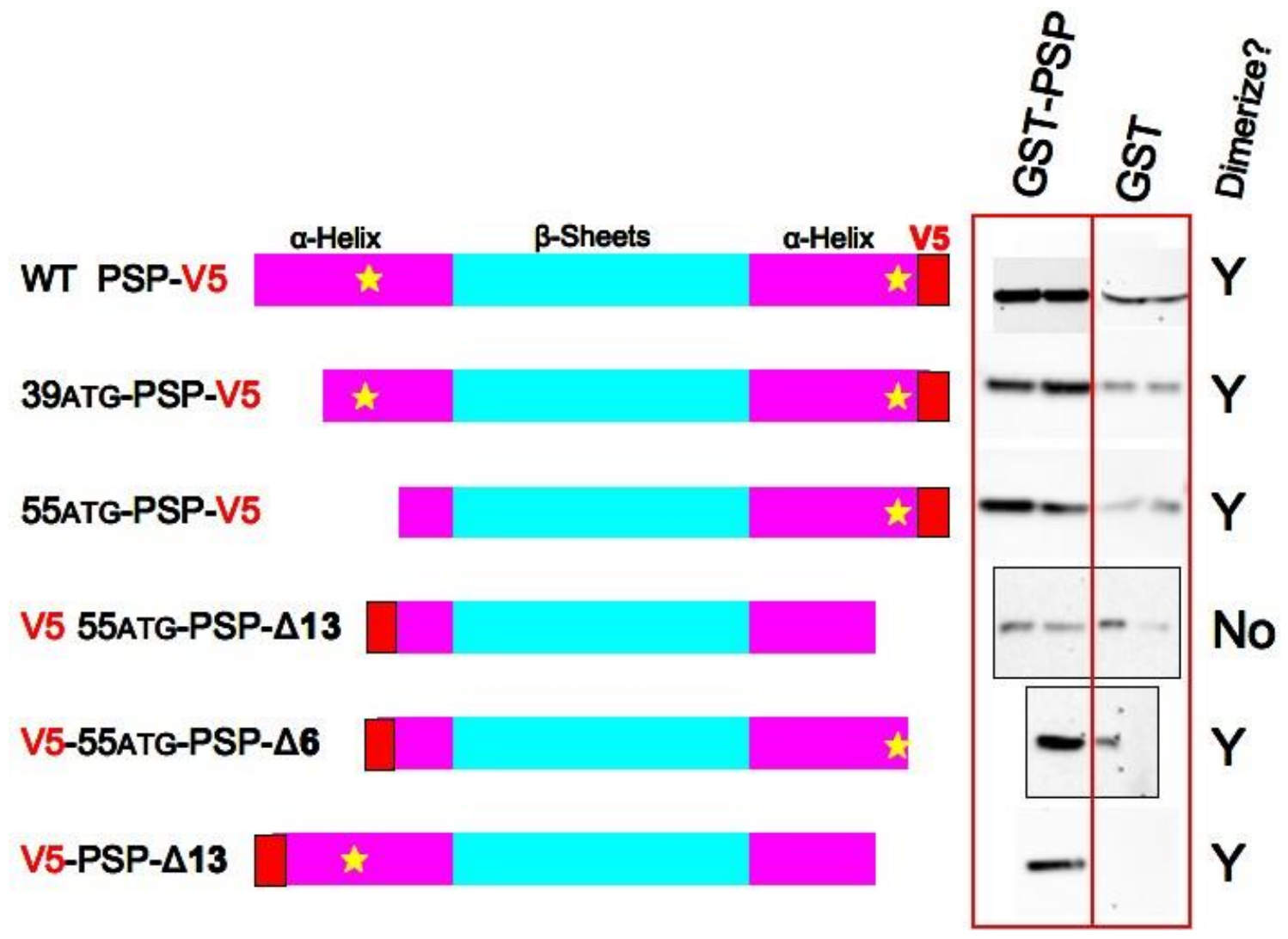

Figure 26: Deletions were designed to test the importance of the predicted hydrogen bonds (stars). Full length GST-PSP was used on the resin to test binding of each reticulocyte lysate mutant shown above.

The first PSP sequence in Figure 26 shows the wild type (WT) PSP-V5 protein, having both $\mathrm{N}$ - and $\mathrm{C}$-terminal hydrogen bond areas. When wild type goes onto the resin, strong binding is seen with GST-PSP resin and weak binding to GST alone. When the protein sequence becomes smaller on the N- terminal side, 39ATG-PSP-V5, but still possesses the hydrogen bond sites, results show binding to GST-PSP resin. If we delete the N-terminal hydrogen bond sites (55ATG-PSP-V5) but keep the C-terminal sites, 
binding to the GST-PSP resin remains. Similarly if we were to delete the C-terminal hydrogen bond sites and keep the N-terminal sites using mutant V5-PSP- $\Delta 13$ binding to the GST-PSP resin remains. If both $\mathrm{N}$ - and C-terminal bond sites are absent, mutant V555ATG-PSP- $\Delta 13$, results show little to no binding to the GST-PSP resin, similar to the negative control GST resin. In conclusion, we can see that if there are hydrogen bond sites available, possible dimer formation can occur with the GST-PSP resin. However when all hydrogen bonds are absent from the mutant PSP there is no sign of dimerization with GST-PSP resin. These results show that both the $\mathrm{N}$ - and C-terminal hydrogen bond sites are essential to dimerization.

\section{DIMERIZATION AND LIPID BINDING}

There is strong evidence to support the idea that the presence or absences of hydrogen bonds from PSP monomers are vital to dimerization. It is also important to see whether these hydrogen bonds affect lipid binding. Using the same lipid binding protocol from the methods section several PSP clones were incubated to evaluate lipid binding. Specific lipids were spotted on nitrocellulose membranes and blocked with $1 \%$ non-fat milk in PBST [50mM phosphate buffer, $150 \mathrm{mM}$ sodium chloride $(\mathrm{NaCl})$, and $0.1 \%$ Tween-20] for 1 hour. After blocking the strips the membranes were incubated with different PSP clones translated in reticulocyte lysates in the same buffer. After an hour at room temperature, the membranes were then washed and protein was detected using antiPSP $(1: 10,000)$ followed by an anti-rabbit $\operatorname{IgG}(1: 5,000)$. Signal solution was added and captured under a Kodak imaging machine. The lipid binding experiments were preformed with four different PSP mutations as shown in Figure 27. 
Figure 27: Lipid Binding with PIP's.

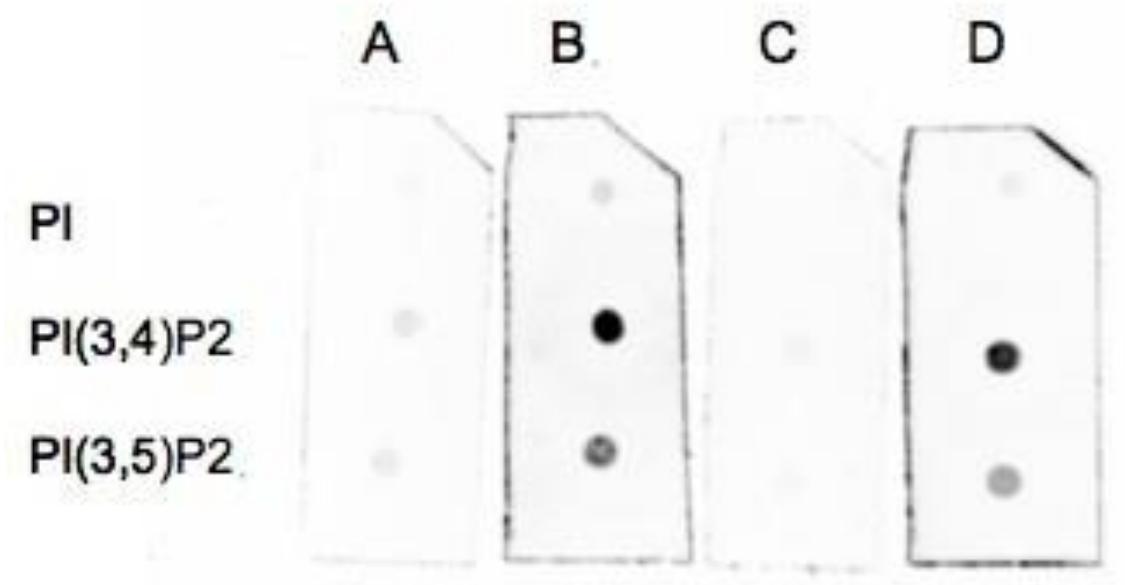

Figure 27: On each membrane there are 3 lipids spotted on the membranes shown on the right in Figure 27. Membrane A was incubated with PSP clone PSP- $\Delta 636-V 5$. Membrane B had clone rPSPdss-V5; Membrane C had clone V5-PSPdss- $\Delta 13$; Membrane D had MV5[9]-rPSPdss. Both wild type PSPs show specific binding.

Results show binding to lipids, particularly $\mathrm{PI}(3,4) \mathrm{P} 2$, on membranes of clone $\mathrm{B}$ and D. Both proteins possess hydrogen bond sites available for dimerization. This experiment also showed in membranes $\mathrm{A}$ and $\mathrm{C}$, which had the protein mutations with hydrogen bonds absent on the C-terminal end that there was little to no binding of lipids. This further illustrated the potential importance of the hydrogen bond sites and overwhelming possibility of dimerization due to them. Figure 28 has the summary of the mutants used in the lipid binding studies. 
Figure 28: Lipid Binding PSP Mutants.
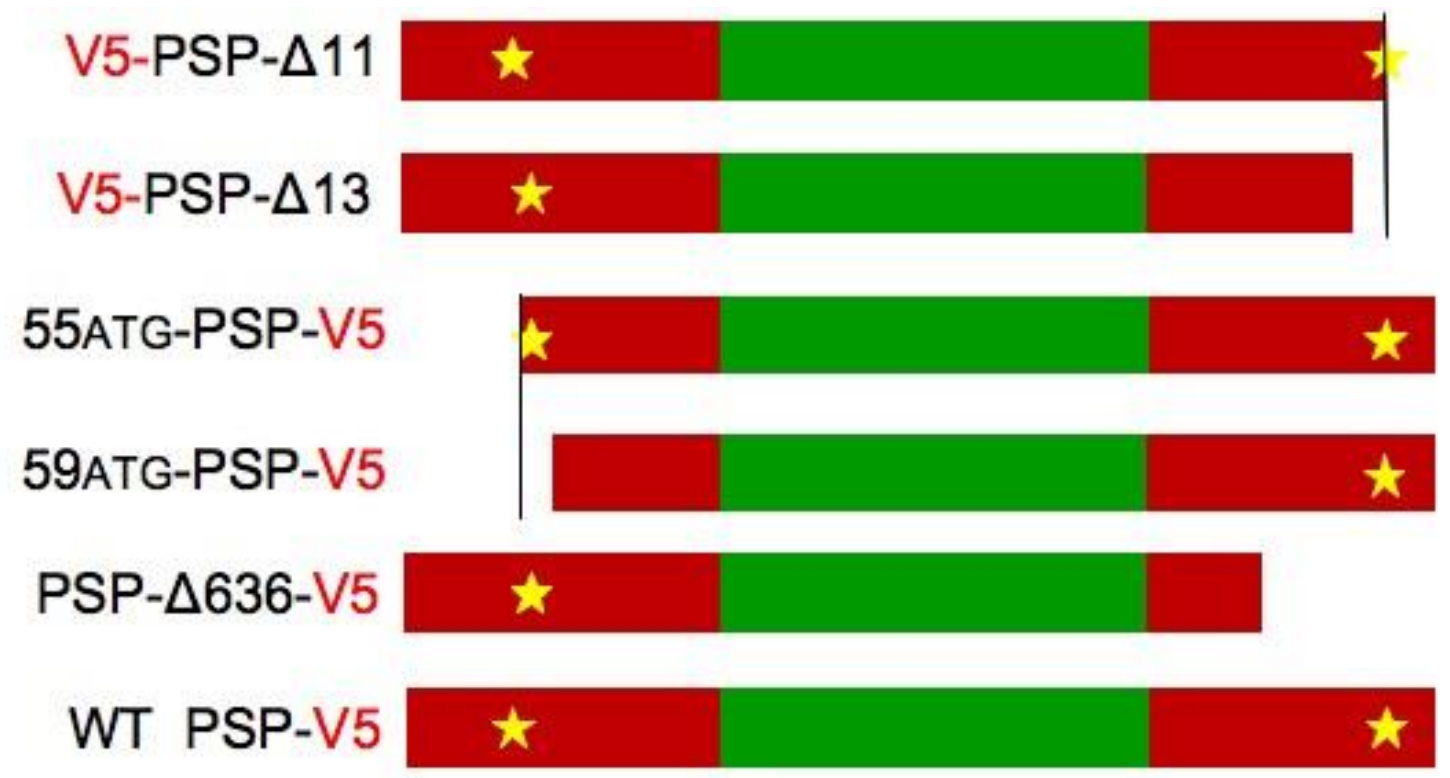

Figure 28: This cartoon illustrates PSP mutants that were translated with reticulocyte lysate and used to test lipid binding. The yellow star indicates the presences or absence of $\mathrm{C}$ or $\mathrm{N}$ terminal hydrogen bond areas within the protein, as shown in Figure 25. 
Figure 29: Results of Lipid Binding of PSP Mutants to PI(3,4)P2.

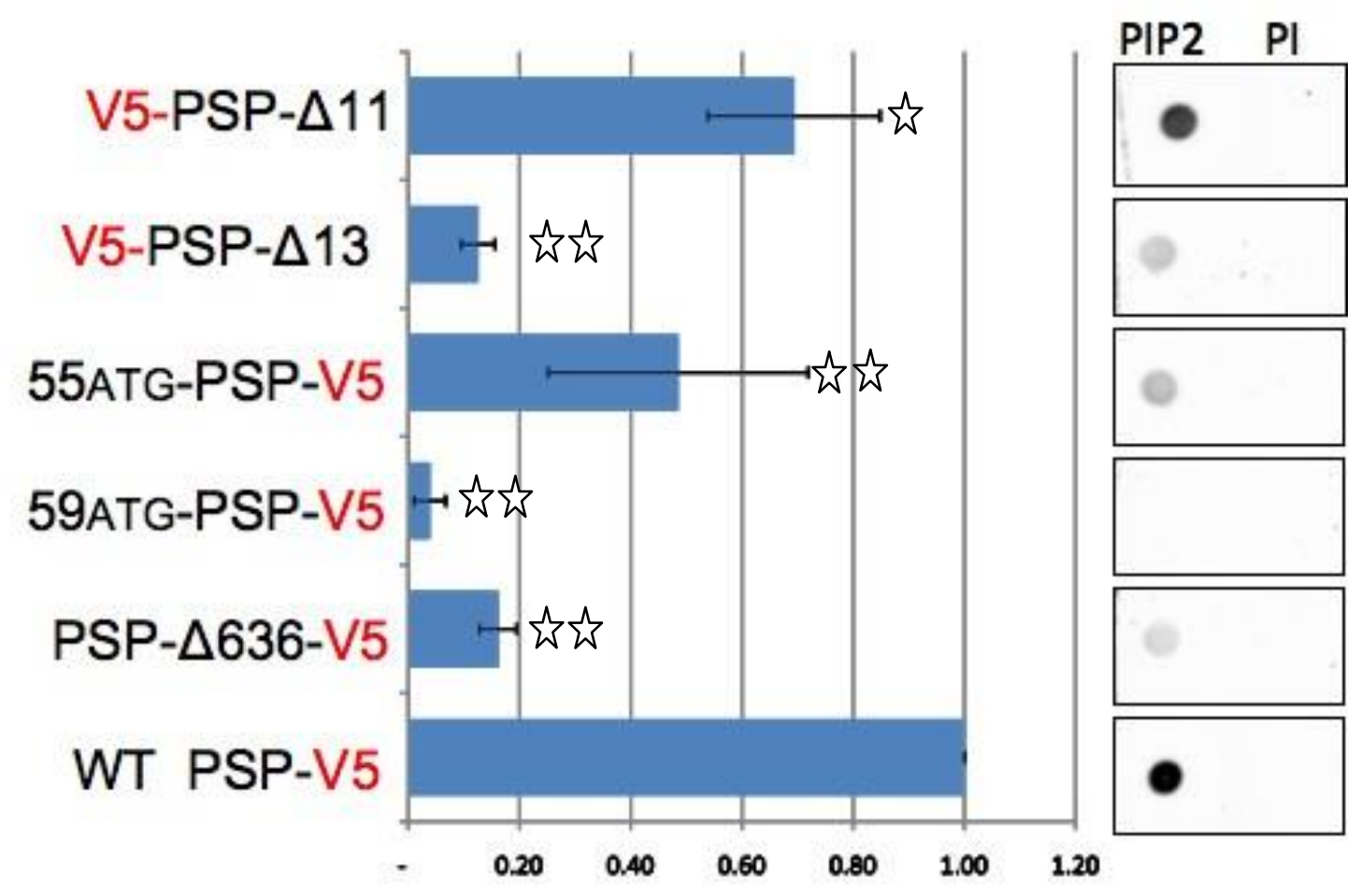

Figure 29: This graph shows the results of the lipid binding studies with mutants to quantify the results with mutants that delete the $\mathrm{N}$-terminal or C-terminal hydrogen

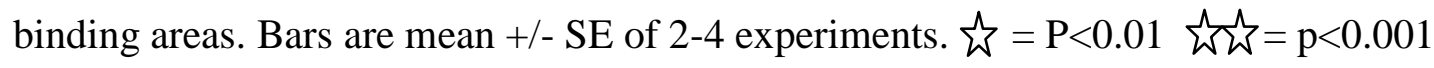
compared to the WT PSP.

Experiments indicate if WT PSP-V5 is translated and allowed to bind to lipids, it will bind PI(3,4)P2 strongly but not PI (control). If the C-terminal is deleted, removing the last 11 amino acids, we see binding of PI(3,4)P2 (termed PIP2). However if we deleted just two more amino acids, which completely remove the C-terminal hydrogen bond area, we get a marked decrease in binding to lipid PI(3,4)P2. The same thing was observed if we delete the N-terminal hydrogen bond sites. PSP mutant 59ATG-PSP-V5 has no hydrogen bond sites on the N-terminal side and in the lipid binding studies shows 
no binding to $\mathrm{PI}(3,4) \mathrm{P} 2$. This confirms the results in Figure 27 and reiterates the importance of hydrogen bond sites in lipid binding. 


\section{DISCUSSION}

\section{PAROTID SECRETORY PROTEIN}

Parotid Secretory Protein (PSP) is one of the major secreted proteins of both rat and human saliva. PSP is part of a sub-family called Palate, lung, nasal epithelium clone (PLUNC). The PLUNC genes are found within a $300 \mathrm{~kb}$ region of human chromosome 20. Palate lung nasal epithelium clone (PLUNC) belongs to a group of proteins which include phospholipids transfer protein (PLTP), cholesterol ester transfer protein (CETP), bactericidal permeablility increasing protein (BPI), and LPS-binding protein (LBP). It is known these proteins play a critical role in host defense against bacteria and due to the homologous relationship with the PLUNC genes it suggests they may also play a role in immunity and host defense in the mouth, nose and upper airways.

The PLUNC gene group was divided into short (SPLUNC1) and long (LPLUNC1) nomenclature based on structural similarities to BPI and protein length. Due to the increased complexity of this gene family, a new nomenclature was developed in which the new root symbol is BPIF\# representing "BPI fold containing." SPLUNC proteins having a short/single domain are now designated by BPIFA and LPLUNC proteins with two or long domains are named BPIFB. The specific name for PSP is BPIFA $_{2}$. PSP is the human protein that is expressed in salivary glands and saliva. Research shows this protein induces agglutination of bacteria, having a powerful antibacterial function as well as having anti-inflammatory properties [31]. Studies also 
show this protein has many isoforms in different tissues meaning they could elicit different properties.

Although the SPLUNC/PSP proteins are gaining more attention, there is still a lot to learn. Defining the mechanism of sorting of PSP will address our broad goal of understanding trafficking in the parotid gland. Extensive research has found that PSP binds lipids. However, before we are able to measure the binding affinity of PSP to lipids it is essential to know the quaternary structure of PSP. We cannot begin to test function, without having a solid understanding of a protein's form. Preliminary data suggests PSP may bind as a dimer opening up questions to PSP form. This is the basis for our research and the main goal of the thesis, to investigate the self-dimerization of PSP. We hypothesize that PSP forms a dimer. We later test our findings in structure and explored possible functions of PSP.

To begin, with our hypothesis in mind, we expressed and purified PSP in Escherichia coli (E.coli). Using the Glutathione-S-transferase gene fusion system, we inserted rPSP cDNA into a pGEX vector, that was unidirectional and contained the Glutathione-S-transferase (GST) affinity tag. This allowed for easy purification of the protein from the bacterial lysate using glutathione sepharose resin. An empty pGEX vector was also made to use as a negative control. In parallel with making a GST-fusion protein, reticulocyte lysates were made using the Promega TNT translational kit to translate rPSP with a V5 epitope tag on the end of it. These proteins were used in the affinity binding experiments used to test our hypothesis.

Preliminary crosslinking data suggests PSP can dimerize, Crosslinking studies were carried out in which isolated native parotid secretory granules were suspended in 
sucrose-HEPES buffer. Granules were then incubated at room temperature for 2 minutes with $0.1 \%$ Formaldehyde. Samples were boiled using SDS loading dye with $\beta \mathrm{MCE}$ and loaded onto a SDS-PAGE gel and transferred to a western membrane. Intact native PSP granules crosslinked into a $45 \mathrm{kDa}$ complex, twice the size of PSP, suggesting dimerization.

\section{STRUCTURE OF PSP}

It is important to have a good understanding of structure so that we may better predict function. In order to studying possible dimerization of PSP, models were generated using computer model programs. We used a computer model program, ITasser, to model the monomer structure of PSP. An amino acid sequence was submitted to the I-Tasser server and the resulting model of PSP showed several characteristics. The secondary structure has a series of beta-pleated sheets that are rolled into a long barrel shape. PSP also possesses three alpha helixes that run the length of the barrel. The monomer structure of PSP mirrors many of the short PLUNC proteins now know as BPIFA.

Given the results of the crosslinking experiments, it gave us reason to use the monomer models of PSP, with an additional computer program to predict possible dimers. The program used was named SymmDock. The SymmDock algorithm program predicted sixteen different dimer models. Ten of the predictions were a stacked model formation and the other six were a head-to-head model. The head-to-head model seemed particularly interesting given the resemblance to long PLUNC group and the BPI proteins. The BPI protein has a long hollow cylinder shape similar to PSP head-to-head 
dimer structure. We studied each predicted model and eliminated the likelihood of them based on our experiments as well as looking at bond formation.

Using the PSP sequence we made proteins with mutations and truncations in different areas of the sequence. These truncations were known to disrupt and inhibit lipid binding. The stacked PSP dimer model has many configurations by just rotating one or both monomer models. If these mutations disrupted lipid binding they could have a significant affect on the formation of the dimer. Using the affinity binding protocol to test whether wild type (WT) PSP would bind to the mutation, we found binding in all three mutants. These results suggested that the charged amino acids that participate in lipid binding do not directly participate in dimer formation. Further, it shows that disrupting the charge and polarity pattern across the surface of PSP did not prevent dimerization. So we decided to focus our efforts on the head-to-head PSP dimer model.

In the head-to-head model from SymmDock computer program, it shows that there are essential hydrogen bond sites possibly involved in the dimerizaion of PSP. These hydrogen bonds are located between the $\mathrm{N}$ and C-terminal ends of the PSP monomer. Several different PSP clones were constructed with deletions of one or both ends containing these hydrogen bond sites. The affinity binding protocol was used with WT GST-PSP on the resin and from our results we can conclude that both $\mathrm{N}$ and Cterminal ends of the mutated PSP monomer translated in the reticulocyte lysate must be deleted in order to disrupt dimer formation. If you add back a single $\mathrm{N}$ or $\mathrm{C}$ terminal area with potential hydrogen binding sites you get dimerization formation with the WT PSP protein on the resin. After repeated experiments, our conclusion was that PSP dimerizes using the essential hydrogen bonding sites presented in the head-to-head dimer model. 
With the results of our experiments and the strength of our computer modeling, and the resemblance to BPI the evidence of PSP dimerizing is strong.

Given the possibility PSP forming a dimer, we further explore the idea of function. There is not a lot of research on the function of PSP, however, we do know that PSP binds to Phosphatidylinositol $(3,4)$ Bisphosphate [37]. Recent research also shows that PSP binds to the sugars of lipopolysaccarides (LPS) [48] and can reduce biofilms confirming antimicrobial activity. With the understanding that PSP binds as a dimer we take a closer look at the different mutations of PSP and how it interacts with PIPs.

Protein-overlay assays were used to quantify PSP binding to lipid membranes. First, lipid binding experiments were carried out by spotting lipids on the nitrocellulose membranes. The lipids strips were then blocked for one hour and later incubated with 20 $\mu$ Ls of TNT reticulocyte lysate. Proteins were then washed and detected with primary and secondary antibodies.

Rat PSP is 235 amino acids long; deletion of 13 amino acids from the C-terminus removed 3 predicted hydrogen bonds important for dimerization, and the resulting protein did not bind PtdIns(3,4)P2. Similarly, deletion of a group of hydrogen bonds near the Nterminus disrupted both dimerization and binding to PtdIns(3,4)P2. Results show that PSP forms a homodimer in the lipid binding studies. In conclusion, not only have we found that PSP forms a dimer similar to BPI, but we showed binding of PSP to phosphatidylinositol 3,4-bisphosphate in lipid membranes is a specific interaction which requires dimerization. We suggest that this binding of PSP to secretory granule membranes contributes to sorting for secretion. 


\section{REFERENCES}

1. Mandel I: The role of saliva in maintaining oral homeostasis. $J$ Am Dent Assoc 1989, 119(2):298-304.

2. Cooper J, Fu K, Marks J, Silverman S: Late effects of radiation therapy in the head and neck region. Int J Radiat Oncol Biol Phys 1995, 31(5):1141-1164.

3. Atkinson J, Wu A: Salivary gland dysfunction: causes, symptoms, treatment. J Am Dent Assoc 1994, 125(4):409-416.

4. Ship JA, Fischer DJ: The Relationship Between Dehydration and Parotid Salivary Gland Function in Young and Older Healthy Adults. J Gerontol A Biol Sci Med Sci 1997, 52A(5):M310-319.

5. Brown LR, Dreizen S, Daly TE, Drane JB, Handler S, Riggan LJ, Johnston DA: Interrelations of Oral Microorganisms, Immunoglobulins, and Dental Caries Following Radiotherapy. Journal of Dental Research 1978, 57(9):882-893.

6. Narhi T, Vehkalahti M, Siukosaari P, Ainamo A: Salivary findings, daily medication and root caries in the old elderly. Caries Res 1998, 32(1):5-9.

7. Valdez I, Fox P: Interactions of the salivary and gastrointestinal systems. I. The role of saliva in digestion. Dig Dis 1991, 9(3):125-132.

8. Korsten M, Rosman A, Fishbein S, Shlein R, Goldberg H, Biener A: Chronic xerostomia increases esophageal acid exposure and is associated with esophageal injury. Am J Med 1991, 90(6):701-706.

9. Gibson G, Barrett E: The role of salivary function on oropharyngeal colonization. Spec Care Dentist 1992, 12(4):153-156.

10. Yagiela JA DF, Johnson BS, et al.: Pharmacology and Therapeutics for Dentistry. 6th edition. St. Louis: Mosby Elsevier; 2011.

11. Keefe D, Schubert M, Elting L, Sonis S, Epstein J, Raber-Durlacher J, Migliorati C, McGuire D, Hutchins R, Peterson D: Updated clinical practice guidelines for the prevention and treatment of mucositis. Cancer 2007, 109(5):820-831.

12. Vissink A, Jansma J, Spijkervet FKL, Burlage FR, Coppes RP: ORAL SEQUELAE OF HEAD AND NECK RADIOTHERAPY. Critical Reviews in Oral Biology \& Medicine 2003, 14(3):199-212.

13. Dreyer J, Sakuma Y, Seifert G: [Radiation-induced sialadenitis. Stage classification and immunohistology]. Pathologe 1989, 10(3):165-170.

14. J. W. Zeilstra AV, A. W. T. Konings, R. P. Coppes, L.: Radiation induced cell loss in rat submandibular gland and its relation to gland function. International Journal of Radiation Biology 2000, 76(3):419-429.

15. Coppes R, Zeilstra L, Kampinga H, Konings A: Early to late sparing of radiation damage to the parotid gland by adrenergic and muscarinic receptor agonists. Br J Cancer 2001, 85(7):1055-1063. 
16. Pow E, McMillan A, Leung W, Kwong D, Wong M: Oral health condition in southern Chinese after radiotherapy for nasopharyngeal carcinoma: extent and nature of the problem. Oral Dis 2003, 9(4):196-202.

17. Pajari U, Ollila P, Lanning M: Incidence of dental caries in children with acute lymphoblastic leukemia is related to the therapy used. ASDC J Dent Child 1995, 62(5):349-352.

18. Rodrigues N, Killion L, Hickey G, Silver B, Martin C, Stevenson M, Mauch P, $\mathrm{Ng} \mathrm{A}$ : A prospective study of salivary gland function in lymphoma patients receiving head and neck irradiation. Int J Radiat Oncol Biol Phys 2009, 75(4):1079-1083.

19. Jensen S, Pedersen A, Vissink A, Andersen E, Brown C, Davies A, Dutilh J, Fulton J, Jankovic L, Lopes $\mathrm{N}$ et al: A systematic review of salivary gland hypofunction and xerostomia induced by cancer therapies: prevalence, severity and impact on quality of life. Support Care Cancer, 18(8):1039-1060.

20. Voutetakis A, Bossis I, Kok MR, Zhang W, Wang J, Cotrim AP, Zheng C, Chiorini JA, Nieman LK, Baum BJ: Salivary glands as a potential gene transfer target for gene therapeutics of some monogenetic endocrine disorders. J Endocrinol 2005, 185(3):363-372.

21. Helmerhorst EJ, Oppenheim FG: Saliva: a Dynamic Proteome. Journal of Dental Research 2007, 86(8):680-693.

22. Perez P, Rowzee A, Zheng C, Adriaansen J, Baum B: Salivary epithelial cells: an unassuming target site for gene therapeutics. Int J Biochem Cell Biol, 42(6):773-777.

23. Wu MM, Grabe M, Adams S, Tsien RY, Moore H-PH, Machen TE: Mechanisms of pH Regulation in the Regulated Secretory Pathway. J Biol Chem 2001, 276(35):33027-33035.

24. Kim T, Gondre-Lewis MC, Arnaoutova I, Loh YP: Dense-Core Secretory Granule Biogenesis. Physiology 2006, 21(2):124-133.

25. Arvan $\mathrm{P}$, Castle $\mathrm{J}$ : Isolated secretion granules from parotid glands of chronically stimulated rats possess an alkaline internal $\mathbf{p H}$ and inwarddirected H+ pump activity. J Cell Biol 1986, 103(4):1257-1267.

26. Venkatesh SG, Cowley DJ, Gorr S-U: Differential aggregation properties of secretory proteins that are stored in exocrine secretory granules of the pancreas and parotid glands. Am J Physiol Cell Physiol 2004, 286(2):C365371.

27. Gorr S-U, Venkatesh SG, Darling DS: Parotid Secretory Granules: Crossroads of Secretory Pathways and Protein Storage. Journal of Dental Research 2005, 84(6):500-509.

28. Castle D, Castle A: Intracellular Transport and Secretion of Salivary Proteins. Critical Reviews in Oral Biology \& Medicine 1998, 9(1):4-22.

29. Bingle C, Seal R, Craven C: Systematic nomenclature for the PLUNC/PSP/BSP30/SMGB proteins as a subfamily of the BPI foldcontaining superfamily. Biochem Soc Trans, 39(4):977-983.

30. Bingle $C$, Bingle L, Craven $C$ : Distant cousins: genomic and sequence diversity within the BPI fold-containing (BPIF)/PLUNC protein family. Biochem Soc Trans, 39(4):961-965. 
31. Bingle CD, Craven CJ: PLUNC: A novel family of candidate host defence proteins expressed in the upper airways and nasopharynx. Hum Mol Genet 2002, 11(8):937-943.

32. Bingle C, LeClair E, Havard S, Bingle L, Gillingham P, Craven C: Phylogenetic and evolutionary analysis of the PLUNC gene family. Protein Sci 2004, 13(2):422-430.

33. Gray PW, Flaggs G, Leong SR, Gumina RJ, Weiss J, Ooi CE, Elsbach P: Cloning of the cDNA of a human neutrophil bactericidal protein. Structural and functional correlations. J Biol Chem 1989, 264(16):9505-9509.

34. Martin TR: Recognition of Bacterial Endotoxin in the Lungs. Am J Respir Cell Mol Biol 2000, 23(2):128-132.

35. Bingle C, Bingle L: Characterisation of the human plunc gene, a gene product with an upper airways and nasopharyngeal restricted expression pattern. Biochim Biophys Acta 2000, 1493(3):363-367.

36. Venkatesh SG, Goyal D, Carenbauer AL, Darling DS: Parotid Secretory Protein Binds Phosphatidylinositol $(\mathbf{3 , 4})$ Bisphosphate. Journal of Dental Research, 90(9):1085-1090.

37. Venkatesh SG, Goyal D, Carenbauer AL, Darling DS: Parotid Secretory Protein Binds Phosphatidylinositol $(\mathbf{3 , 4})$ Bisphosphate. Journal of Dental Research:0022034511410699.

38. Smith D, Johnson K: Single-step purification of polypeptides expressed in Escherichia coli as fusions with glutathione S-transferase. Gene 1988, 67(1):31-40.

39. Dowler S, Currie R, Campbell D, Deak M, Kular G, Downes C, Alessi D: Identification of pleckstrin-homology-domain-containing proteins with novel phosphoinositide-binding specificities. Biochem J 2000, 351(Pt 1):19-31.

40. Shimono C, Manabe R-i, Yamada T, Fukuda S, Kawai J, Furutani Y, Tsutsui K, Ikenaka K, Hayashizaki Y, Sekiguchi K: Identification and characterization of nCLP2, a novel C1q family protein expressed in the central nervous system. $J$ Biochem, 147(4):565-579.

41. Kakunaga S, Ikeda W, Itoh S, Deguchi-Tawarada M, Ohtsuka T, Mizoguchi A, Takai Y: Nectin-like molecule-1/TSLL1/SynCAM3: a neural tissue-specific immunoglobulin-like cell-cell adhesion molecule localizing at non-junctional contact sites of presynaptic nerve terminals, axons and glia cell processes. $J$ Cell Sci 2005, 118(6):1267-1277.

42. Schneidman-Duhovny D, Inbar Y, Nussinov R, Wolfson HJ: PatchDock and SymmDock: servers for rigid and symmetric docking. Nucleic Acids Res 2005, 33(suppl_2):W363-367.

43. Schneidman-Duhovn... D, Inbar Y, Nussinov R, Wolfson H: Geometry-based flexible and symmetric protein docking. Proteins 2005, 60(2):224-231.

44. Kolodziejczyk R, Kochman M, Bujacz G, Dobryszycki P, Ozyhar A, Jaskolski M: Crystallization and preliminary crystallographic studies of juvenile hormone-binding protein from Galleria mellonella haemolymph. Acta Crystallogr D Biol Crystallogr 2003, 59(Pt 3):519-521. 
45. Beamer LJ, Carroll SF, Eisenberg D: Crystal Structure of Human BPI and Two Bound Phospholipids at 2.4 Angstrom Resolution. Science 1997, 276(5320):1861-1864.

46. Chaudhury S, Gray J: Conformer selection and induced fit in flexible backbone protein-protein docking using computational and NMR ensembles. J Mol Biol 2008, 381(4):1068-1087.

47. Kolodziejczyk R, Bujacz G, Jakob M, Ozyhar A, Jaskolski M, Kochman M: Insect juvenile hormone binding protein shows ancestral fold present in human lipid-binding proteins. J Mol Biol 2008, 377(3):870-881.

48. Hirt H, Gorr S-U: The Antimicrobial Peptide GL13K is Effective in Reducing Biofilm of Pseudomonas aeruginosa. Antimicrob Agents

Chemother:AAC.00311-00313. 


\section{CURRICULUM VITAE}

\section{Diana M. Blau}

2400 Mellwood Ave. Apt. 812, Louisville, KY 40206

dmblau01@,louisville.edu

\section{EDUCATION}

(206) 612-0905

\begin{tabular}{ll}
\hline University of Louisville & Louisville, KY \\
D.M.D & Expected May 2014 \\
M.S., Oral biology & Expected Dec. 2013 \\
- Masters Thesis : "Dimerization of Parotid Secretory Protein ” & \\
$\begin{array}{l}\text { University of Wisconsin - Madison } \\
\text { B.S., Biology }\end{array}$ & Madison, WI
\end{tabular}

\section{RESEARCH}

Master's Thesis explored:

2009-2013

- Quaternary structure of Parotid Secretory Protein (PSP)

- PSP's lipid binding activity to phosphatidylinositol phosphates

Obtained Summer Research Grant

Summer 2009

\section{PRESENTATIONS}

American Association for Dental Research Annual Meeting Washington D.C.

Oral Presentation "Dimerization of Parotid Secretory Protein"

Research Louisville

Fall 2009

Louisville, KY

Poster Presentation "Probing the Dimerization of Parotid Secretory Protein"

Won Travel award to AADR Annual Meeting

Gordon Research Conf., Proprotein Processing, Trafficking \& Secretion July 2012

Poster "Lipid binding by Parotid Secretory Protein (BPIF A2e) requires Dimerization."

\section{TEACHING / LEADERSHIP}

Active member of:

Louisville American Student Dental Association (LASDA) 2010-2014

American Dental Education Association

2010-2014

- Preside as President of local student chapter for three years

- National Ohio Valley Regional Representative

2011-2014 
- University of Louisville Student Representative at Annual Meetings

- Coordinated events around school to better educate students on:

-Specialty Programs

-National Board Examinations

-Licensure Exams

-Issues facing Dental Education

\section{Remote Area Medical}

Treasurer

2010-2014

Helped recruit and manage participates at different RAM clinics

Teaching assistant for D1 Introduction to Clinical Dentistry

Participated in mentoring programs for younger classmen

2011-2014

\section{SERVICE}

Remote Area Medical (RAM)

Rendered free dental services at 8 weekend clinics in KY and TN

2010-2014

Oral Health Fair

Educated and provided oral cancer screenings to the public

2013

Smile Kentucky

-Educated young children on healthy diet and oral hygiene habits

2008-2014

-Provided dental services

Bike-cuspid Race and Run

Awarded over $\$ 600.00$ in student funding for event

Raised over $\$ 1000.00$ for charity

Participated in Oral Cancer Walk

Helped raise awareness for oral health screening

REFERENCES

Dr. Douglas Darling

501 S. Preston Street

Louisville, KY 40202

douglas.darling@louisville.edu

Dr. Brian Shumway

501 S. Preston Street

Louisville, KY 40202

brian.shumway@louisville.edu

\section{Dr. Pauletta Gay Baughman}

501 S. Preston Street Rm 042

Louisville, KY 40202

pgbaug01@louisville.edu 